\title{
Association of Tumour Microenvironment with Protein Glycooxidation, DNA Damage, and Nitrosative Stress in Colorectal Cancer
}

\author{
Justyna Zińczuk (D) \\ Konrad Zaręba ${ }^{2}$ \\ Joanna Kamińska (iD) \\ Olga Martyna Koper- \\ Lenkiewicz iD' \\ Violetta Dymicka-Piekarska (D) \\ Anna Pryczynicz ${ }^{3}$ \\ Katarzyna Guzińska-Ustymowicz ${ }^{3}$ \\ Boguław Kędra² \\ Joanna Matowicka-Karna (iD) \\ Małgorzata Żendzian-Piotrowska ${ }^{4}$ \\ Anna Zalewska ${ }^{5}$ \\ Mateusz Maciejczyk ${ }^{4}$ \\ 'Department of Clinical Laboratory \\ Diagnostics, Medical University of \\ Bialystok, Białystok, 15-269, Poland; ${ }^{2} 2$ nd \\ Clinical Department of General and \\ Gastroenterological Surgery, Medical \\ University of Bialystok, Białystok, 15-276, \\ Poland; ${ }^{3}$ Department of General \\ Pathomorphology, Medical University of \\ Bialystok, Białystok, 15-269, Poland; \\ ${ }^{4}$ Department of Hygiene, Epidemiology \\ and Ergonomics, Medical University of \\ Bialystok, Białystok, 15-222, Poland; \\ ${ }^{5}$ Independent Laboratory of Experimental \\ Dentistry, Medical University of Bialystok, \\ Białystok, I5-276, Poland
}

Correspondence: Justyna Zińczuk Department of Clinical Laboratory Diagnostics, Medical University of Bialystok, Waszyngtona I5a St., Białystok, 15-269, Poland

Tel +48 858318716

Email justyna.zinczuk@umb.edu.pl

Mateusz Maciejczyk Department of Hygiene, Epidemiology and Ergonomics, Medical University of Bialystok, Mickiewicza 2c St., Białystok, 15-222, Poland

Tel +48 857485585

Email mat.maciejczyk@gmail.com
Purpose: In this study, we evaluated the total antioxidant capacity, nitrosative stress, and protein/DNA oxidation and glycoxidation products in patients with colorectal cancer regarding histopathological parameters associated with the tumour microenvironment, such as inflammatory infiltration and tumour budding and compare all determined parameters between tumours located in the right and left side of the colon and normal mucosa.

Patients and Methods: Ferric reducing antioxidant power (FRAP), nitrosative stress (myeloperoxidase (MPO), nitrogen oxide (NO), peroxynitrite, and nitrotyrosine), protein oxidation products (protein carbonyls (PC), total thiols, and ischemia modified albumin (IMA)), protein glycooxidation products (tryptophan, kynurenine, N-formylkynurenine, dityrosine, Amadori product, advanced glycation end products (AGE)) and 8-hydroxydeoxyguanosine $(8-\mathrm{OHdG})$ were measured in homogenates from normal and cancerous tissue of 30 patients with colorectal cancer.

Results: Levels of FRAP ( $p=0.0009)$, IMA $(p=0.0002)$, kynurenine $(p<0.0001)$, $\mathrm{N}$-formylkynurenine $(\mathrm{p}<0.0001)$, dityrosine $(\mathrm{p}<0.0001)$, Amadori products $(\mathrm{p}=0.0024)$, AGE $(p<0.0001)$, MPO $(p<0.0001)$, NO $(p<0.0001)$ and nitrotyrosine $(p=0.0011)$ were increased, whereas PC $(\mathrm{p}=0.0004)$, tryptophan $(\mathrm{p}<0.0001), 8-\mathrm{OHdG}(\mathrm{p}<0.0001)$ and peroxynitrite $(\mathrm{p}=0.0003)$ were decreased in the left-side tumour compared to the right-side tumour and normal mucosa.

Conclusion: Our results showed that colorectal cancer is related with disturbances in antioxidant defense and increased oxidative and nitrosative damages to proteins and DNA. These parameters may be useful for evaluation the progression and differentiation of the tumour location. We also demonstrated that redox indicators may depend on the histological type of the tumour and may influence tumour invasion depth, presence of lymph node and distant metastasis, vascular and neural invasion, inflammatory infiltration, and tumour budding, which are part of the tumour microenvironment.

Keywords: oxidative stress, nitrosative stress, redox biomarkers, colorectal cancer

\section{Introduction}

Cancer is the second most common cause of death globally, responsible for one in six deaths in 2018. ${ }^{1}$ The most common type of cancer is colorectal cancer, which caused over 1.8 million new cases and about 9555,027 deaths in 2018 . $^{2}$ According to the GLOBOCAN database, the number of cancer incidence will increase from 18.1 million in 2018 to over 29.5 million in $2040 .^{3}$ Unfavourable statistics regarding the number of deaths are caused by advanced CRC stage when the patient developed metastases commonly in the liver and the lungs. ${ }^{4}$ Treatment of patients 
diagnosed in stage IV of CRC with surgical resection, chemotherapy, precision cancer medicines, or immunotherapy is often ineffective. ${ }^{5}$ Therefore, understanding the biology of CRC and the mechanisms involved in the metastasis process is essential to improve survival rates in these patients.

In 1990 Bufill observed that CRC pathogenesis differs between tumours localized in the colon's left and right side. ${ }^{6}$ Tumours in both locations are characterized by different molecular characteristics and histology. Rightside tumours are often sessile serrated adenomas or mucinous adenocarcinomas (muc adc), and microsatellite instability-high (MSI-high) is typical for these tumours. In contrast, left-side tumours have polypoid morphology likely to show villous or tubular lesions and adenocarcinomas (adc), and show a tendency to have chromosomal instability-high (CIN-high). ${ }^{5,6} \mathrm{CIN}$ molecular pathway is characterized by the inactivation or deletion of oncogenes and tumour suppressor genes and other mutations $(A P C$, TP53, KRAS, NRAS, SMAD4, PIK3CA, FBXW7, and TCF7L2), whereas defects in the DNA mismatch repair system (MSH2, MLH1, MSH6, MSH3, PMS2, MLH3, and Exo2) are typical for MSI pathway. ${ }^{7}$ However, the exact causes of the differences between left- and right-side cancers are not well known.

Oxidative and nitrosative stress are one of the most important mechanisms responsible for DNA damages. They are defined as a lack of balance between the generation and accumulation of reactive oxygen (ROS) and nitrogen (RNS) species and the efficiency of enzymatic and non-enzymatic antioxidant protection. ${ }^{8}$ It has been observed that cancer cells that grow in low oxygen environment have an ability to enhance the production of reactive oxygen and nitrogen species, which is a response to hypoxia. ROS and RNS may regulate many physiological processes in low concentrations, but their overproduction may be an important factor of cell structure damages, including lipids, cell membranes, proteins, and DNA. ${ }^{9}$ Moreover, oxidative and nitrosative stress through numerous genetic events (DNA damage and genomic instability) and alterations in cell signaling, transcription factors, ubiquitin/proteasomal/ lysosomal/autophagy-mediated protein degradation may contribute to impairment of cellular homeostasis. It may have influence tumour's microenvironment and its growth. ${ }^{10}$ In recent years scientists focused on tumour microenvironment, especially inflammatory infiltrations, as potential treatment goals. ${ }^{11}$
Therefore, our study aimed to evaluate the total antioxidant capacity, nitrosative stress, and protein/DNA oxidation and glycoxidation products in colon cancer tissue compared to normal mucosa and compared to all determined parameters between left-side, right-side tumours, and normal mucosa. In our previous paper, ${ }^{12}$ we demonstrated that catalase and xanthine oxidase activity were associated with the intensity of inflammatory infiltration, whereas the malondialdehyde level was associated with a number of budding tumours. Nevertheless, still little is known about CRC progression and metastasis. Therefore, in this paper, we evaluate novel parameters of nitrosative stress and protein/DNA oxidation and glycoxidation products in patients with CRC in relation to tumour microenvironment components, such as vascular or neural invasion, tumour budding or inflammatory infiltration.

\section{Patients and Methods}

The study was approved by the Bioethics Committee of the Medical University of Bialystok, Poland (permission number R-I-002/48/2019). After a detailed explanation of the purpose of our research and the possible risk, all the qualified patients agreed in writing to participate in the experiment. The research was performed in accordance with the Guidelines for Good Clinical Practice and the Declaration of Helsinki for ethical principles for medical research involving human subjects.

\section{Patients and Tissue Samples}

The study included 30 patients treated surgically due to colorectal cancer in the 2nd Clinical Department of General and Gastroenterological Surgery at the Medical University of Bialystok Clinical Hospital in 2017-2020. Patients of both sexes without comorbidities who were not treated with radiotherapy or chemotherapy prior to surgery were enrolled in the study. The exclusion criteria in patients with CRC included any systemic or autoimmune diseases (diabetes, insulin resistance, hypertension, coronary heart disease, rheumatoid arthritis, and psoriasis) as well as lung, thyroid, liver, kidney, gastrointestinal and infectious diseases (HCV and HIV infection) and immunity disorders. Additionally, smokers and patients taking drugs (antibiotics, non-steroidal anti-inflammatory drugs, glucocorticosteroids, vitamins, and dietary supplements) for the last three months were excluded from the study.

The time from diagnosing a patient with cancer to the surgery varied from a minimum of two days to a maximum of four weeks. The study material was 
collected from all patients during surgical resection of tumour. Each patient had the following samples taken: normal mucosa (adjacent non-tumour tissue) and tumour tissue. Normal mucosa was collected from the corresponding adjacent tissue away from the tumour border (histologically examined). After resection, the obtained material was placed in a container with liquid nitrogen and frozen at $-80^{\circ} \mathrm{C}$.

\section{Histopathological Analysis}

Histopathological diagnosis was established based on haematoxylin and eosin $(\mathrm{H}+\mathrm{E})$ staining. It included the following parameters: histological type and the grade of histological malignancy according to the World Health Organization guidelines, tumour stage according to the TNM classification standard of the Union for International Cancer Control and tumour inflammatory infiltration according to Jass's classification (Figure 1A). ${ }^{13}$ Tumour budding (TB), poorly differentiated clusters (PDC), and areas of poorly differentiated components (APDC) according to ITBCC recommendations also have been assessed. ${ }^{14}$ ITBCC $^{14}$ defined tumour budding as a single tumour cell or small clusters (up to 4 ) of tumour cells. Tumours with $<4$ clusters, 5 to 9 budding foci, and $>10$ budding foci classified as $\mathrm{Bd} 1$ (low budding), $\mathrm{Bd} 2$ (intermediate budding), and $\mathrm{Bd} 3$ (high budding), respectively. ${ }^{14}$ Poorly differentiated clusters (PDC) are defined as cancer clusters in the stroma composed of 5 cancer cells lacking a gland-like structure. ${ }^{15}$ Tumours with $<5$ clusters, 5 to 9 clusters, and $>10$ clusters were classified as G1, G2, and G3. Areas of poorly differentiated components (APDC) have been defined with $<10$ clusters, and those with $>10$ clusters were classified as G1 and G2, respectively. ${ }^{15}$

The characteristics and details of the study group are presented in Table 1.

\section{$\mathrm{H}+\mathrm{E}$ Staining}

Each tumour was cut along a line parallel to the longest tumour axis. Thus, 4 to 8 slices containing cancer cells and the adjacent macroscopically unchanged tissues of 1 $1.5 \mathrm{~cm}$ in size were collected. The tissues were fixed in $10 \%$ buffered formalin for no longer than 24 hours. The specimens were embedded in paraffin at a temperature of $56^{\circ} \mathrm{C}$. Paraffin blocks were cut into $4-\mu \mathrm{m}$-thick sections with a microtome Microm H340. The obtained sections were stained with haematoxylin and eosin, and reviewed

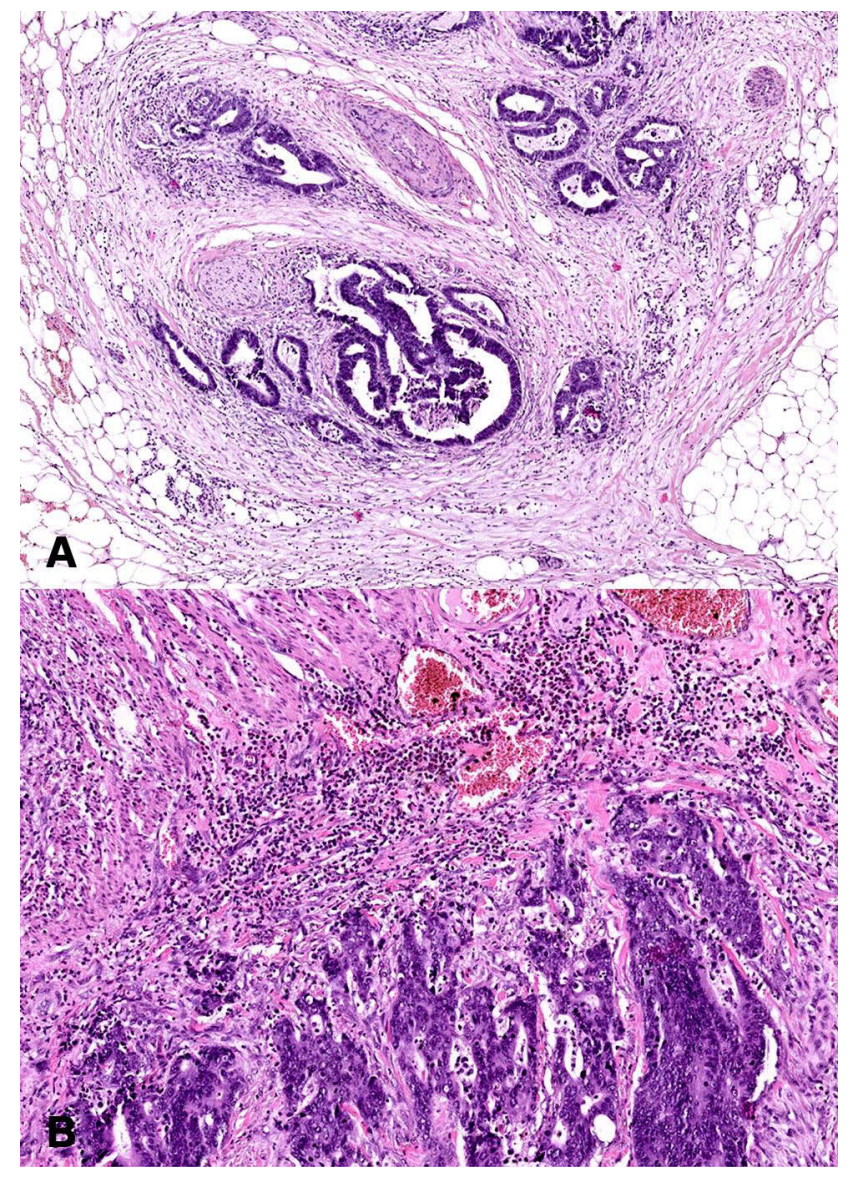

Figure I Histological images of colorectal cancer. (A) Colorectal adenocarcinoma with neural invasion. 50× magnification. (B) Colorectal adenocarcinoma with strong inflammatory cells infiltration. 100x magnification.

by two independent pathologists under a microscope Olympus CX22 with $200 \times$ and $400 \times$ magnification.

\section{Preparation of the Tissues}

On the day of biochemical assays, the tissue samples were slowly thawed at $4{ }^{\circ} \mathrm{C}$, fragmented, weighed, and divided into two equal parts each. One of the parts was diluted in ice-cold phosphate-buffered saline (PBS, 0.02 M, pH 7.4) at a ratio of 1:10 (w/v). Tumour and non-tumour tissues were homogenized on ice with a glass tissue homogenizer (Omni TH, Omni International, Kennesaw, GA, USA), sonicated twice $(1800 \mathrm{~J} / \mathrm{sample}, 20 \mathrm{~s} \times 3$; UP 400S, Hielscher, Teltow, Germany), and then centrifuged $\left(12,000 \times \mathrm{g}, 20\right.$ minutes, $4^{\circ} \mathrm{C} ;$ MPW Med Instruments, Warsaw, Poland) to collect the supernatant and be immediately assayed. ${ }^{16}$ In order to prevent sample oxidation and proteolysis, butylated hydroxytoluene (BHT; $10 \mu \mathrm{L} 0.5 \mathrm{M}$ BHT in acetonitrile/1 mL PBS) and proteolysis inhibitors (Complete Mini Roche, France) were added. ${ }^{17}$ 
Table I Characteristics of the Study Group

\begin{tabular}{|c|c|}
\hline Parameter & n (\%) \\
\hline Age & \\
\hline$<60$ & 5 (16.7\%) \\
\hline$>60$ & 25 (83.3\%) \\
\hline Sex & \\
\hline Male & $16(53.3 \%)$ \\
\hline Female & $14(46.7 \%)$ \\
\hline Location & \\
\hline Left-side & $14(46.7 \%)$ \\
\hline Right-side & $16(53.3 \%)$ \\
\hline Tumour's size & \\
\hline$<3 \mathrm{~cm}$ & $5(16.7 \%)$ \\
\hline$>3 \mathrm{~cm}$ & $25(83.3 \%)$ \\
\hline Histological type & \\
\hline Adenocarcinoma & $25(83.3 \%)$ \\
\hline Mucinous adenocarcinoma & $5(16.7 \%)$ \\
\hline Depth of tumour invasion ( $\mathrm{pT}$ ) & \\
\hline $\mathrm{T} 2$ & $10(33.3 \%)$ \\
\hline T3 & $20(66.7 \%)$ \\
\hline Lymph node metastasis (pN) & \\
\hline No & $18(60.0 \%)$ \\
\hline $\mathrm{NI}+\mathrm{N} 2$ & $12(40.0 \%)$ \\
\hline Distant metastasis (pM) & \\
\hline Mo & $26(86.7 \%)$ \\
\hline MI & $4(13.3 \%)$ \\
\hline Stage at diagnosis & \\
\hline I & $8(26.7 \%)$ \\
\hline II & $8(26.7 \%)$ \\
\hline III & $10(33.3 \%)$ \\
\hline IV & $4(13.3 \%)$ \\
\hline Vascular invasion & \\
\hline Absent & $12(40.0 \%)$ \\
\hline Present & $18(60.0 \%)$ \\
\hline Neural invasion & \\
\hline Absent & $22(73.3 \%)$ \\
\hline Present & $8(26.7 \%)$ \\
\hline $\begin{array}{l}\text { Inflammatory infiltration in the invasive } \\
\text { front }\end{array}$ & \\
\hline Absent and weak & $15(50.0 \%)$ \\
\hline Moderate and strong & $15(50.0 \%)$ \\
\hline $\begin{array}{l}\text { Inflammatory infiltration in the tumour } \\
\text { center }\end{array}$ & \\
\hline Absent and weak & $16(53.3 \%)$ \\
\hline Moderate and strong & $14(46.7 \%)$ \\
\hline
\end{tabular}

(Continued)
Table I (Continued).

\begin{tabular}{|l|l|}
\hline Parameter & n (\%) \\
\hline Tumour budding (TB) & \\
$\mathrm{BdI}$ & $13(43.3 \%)$ \\
$\mathrm{Bd} 2$ & $8(26.7 \%)$ \\
$\mathrm{Bd} 3$ & $9(30.0 \%)$ \\
\hline Poorly differentiated clusters (PDC) & \\
GI & $30(100.0 \%)$ \\
G2 & $0(0.0 \%)$ \\
G3 & $0(0.0 \%)$ \\
\hline Areas of poorly differentiated components & \\
(APDC) & $30(100.0 \%)$ \\
GI & $0(0.0 \%)$ \\
G2 & \\
\hline
\end{tabular}

\section{Redox Assays}

All reagents (unless otherwise stated) were analytical grade and purchased from Sigma-Aldrich Nümbrecht (Germany) or Sigma-Aldrich Saint Louis (MO, USA).

The absorbance/fluorescence was assessed using Infinite M200 PRO Multimode Microplate Reader (Tecan Group Ltd., Männedorf, Switzerland). The fluorescence was assessed in 96-well black-bottom microplates. All determinations were performed in duplicate samples. The results were standardized to $1 \mathrm{mg}$ of total protein. According to the manufacturer's instructions, total protein content was determined spectrophotometrically (Thermo Scientific PIERCE BCA Protein Assay; Rockford, IL, USA).

\section{Total Antioxidant Capacity}

The total antioxidant capacity was determined spectrophotometrically using FRAP (ferric reducing antioxidant power) assay based on the reduction of $\mathrm{Fe}^{3+}$ ions in the form of a complex with 2,4,6-Tri(2-pyridyl)-s-triazine (TPTZ) to $\mathrm{Fe}^{2}$ ${ }^{+}$ions. ${ }^{18}$ The absorbance was assessed at $593 \mathrm{~nm}$.

\section{Protein Oxidation}

The concentration of protein carbonyls (PC) was determined spectrophotometrically using 2,4-dinitrophenylhydrazine (2,4-DNPH). ${ }^{19} \mathrm{PC}$ formed a stable complex with 2,4-DNPH and absorbance was assessed at $593 \mathrm{~nm}$.

The concentration of total thiols was determined spectrophotometrically using Ellman's assay. ${ }^{20}$ The absorbance was assessed at $593 \mathrm{~nm}$, and the total thiol content was 
calculated from the calibration curve for reduced glutathione.

The concentration of ischemia-modified albumin (IMA) was determined spectrophotometrically based on the measurement of the exogenous cobalt $\left(\mathrm{Co}^{2+}\right)$ binding facility of the human serum albumin (HSA) ${ }^{21}$ The absorbance was assessed at $470 \mathrm{~nm}$.

\section{Protein Glycoxidation}

To evaluate the protein glycoxidation rate, the characteristic fluorescence at 295/340 nm (tryptophan), 365/480 nm (kynurenine), 325/434 nm (N-formylkynurenine), and 330/ $415 \mathrm{~nm}$ (dityrosine) was assessed. Immediately before determination, tissue samples were diluted in $0.1 \mathrm{M} \mathrm{H}_{2}$ $\mathrm{SO}_{4}(1: 5, \mathrm{v} / \mathrm{v}){ }^{21,22}$ The results were expressed in arbitrary fluorescence units $(\mathrm{AFU}) / \mathrm{mg}$ protein.

The Amadori product formation was determined spectrophotometrically using nitro blue tetrazolium (NBT) assay. ${ }^{23}$ The absorbance was assessed at $525 \mathrm{~nm}$, and an extinction coefficient of $12,640 \mathrm{~cm}-1 \mathrm{~mol}-1 \mathrm{~L}$ for monoformazan was used.

The formation of advanced glycation end products (AGE) was determined spectrofluorimetrically. The characteristic fluorescence of pyraline, pentosidine, furylfuranyl-imidazole (FFI), and carboxymethyl lysine (CML) was assessed at $350 / 440 \mathrm{~nm} .{ }^{24}$ Immediately before determination, tissue samples were diluted in $0.1 \mathrm{M} \mathrm{H}_{2}$ $\mathrm{SO}_{4}(1: 5, \mathrm{v} / \mathrm{v}){ }^{21}$

\section{DNA Oxidation Products}

8-OHdG level was determined colorimetrically with commercial ELISA kits (Cayman Chemical, Miami, USA; USCN Life Science, Wuhan, China, respectively), according to the manufacturer's instructions.

\section{Nitrosative Stress}

The activity of myeloperoxidase (MPO) was determined spectrophotometrically using sulfanilamide, hexadecyltrimethylammonium, ortho-dianisidine dihydrochloride and $\mathrm{H}_{2} \mathrm{O}_{2} .{ }^{25}$ The absorbance was assessed at $450 \mathrm{~nm}$.

The concentration of total nitric oxide (NO) was determined spectrophotometrically using sulfanilamide and N-(1-naphthyl)-ethylenediamine dihydrochloride. ${ }^{26,27}$ The absorbance was assessed at $490 \mathrm{~nm}$.

The peroxynitrite concentration was determined spectrophotometrically based on peroxynitrite-mediated nitration resulting in the nitrophenol formation. ${ }^{28}$ The absorbance was assessed at $320 \mathrm{~nm}$.
The concentration of S-nitrosothiols was determined spectrophotometrically using Griess's assay based on the reaction with $\mathrm{Cu}^{2+}$ ions. ${ }^{27,29}$ The absorbance was assessed at $490 \mathrm{~nm}$.

According to the manufacturer's instructions, the concentration of nitrotyrosine was determined spectrophotometrically using an ELISA kit (Immundiagnostik AG; Bensheim, Germany).

\section{Statistical Analysis}

Statistical analysis was performed using the GraphPad Prism (GraphPad Software, La Jolla, USA). The ShapiroWilk test was used to examine the distribution of results. For a normal distribution, the Student's $t$-test was used. In the case of the lack of normal distribution, the Mann-Whitney $U$-test was used. For multiple comparisons, the ANOVA test was used with Tukey's post hoc test or the ANOVA Kruskal-Wallis test followed by the Dunn test. The data were presented as median (minimum-maximum). The correlations between the measured parameters were analyzed using Spearman correlation coefficient. Statistical significance was established at $\mathrm{p}<0.05$. The results demonstrated comparisons of left-side vs right-side tumours vs normal adjacent mucosa and other statistically significant differences. All comparisons were presented in the supplementary material (Tables S1 and $\underline{\mathrm{S}}$ ).

\section{Results \\ Clinical Characteristics}

The study included 30 patients with CRC. Tumour location was divided into two groups: left-side (descending colon, sigmoid colon, and rectum) and rightside (caecum, ascending colon, transverse colon). ${ }^{6}$ Right-side colorectal cancer (RCRC) occurred in $46.7 \%$ of patients, whereas left-side (LCRC) in 53.3\% of patients. The tumour differentiation grade in all patients with colorectal cancer in study group was G2 (moderately differentiated). Twenty-five patients had adenocarcinoma, whereas five patients had mucinous adenocarcinoma. About $66 \%$ of patients had a pT3 stage of tumour. Forty percent of patients have lymph node (N1+N2) and $13.3 \%$ have distant metastasis (M1). Sixty percent of patients had a vascular invasion, which defines as "tumour present within an endothelial-lined space either surrounded by a rim of muscle or containing red blood cells". The majority $(73.3 \%)$ of patients had no neural invasion. Neural invasion is 
Total antioxidant capacity

A

FRAP

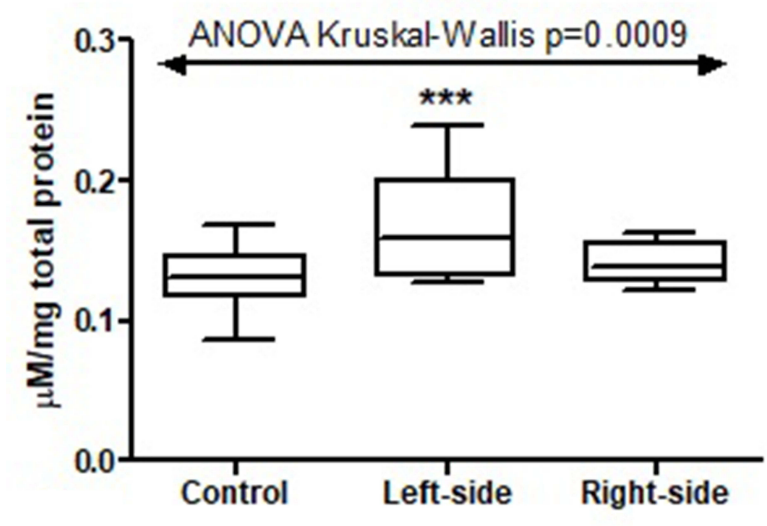

DNA oxidation product

B 8-OHdG

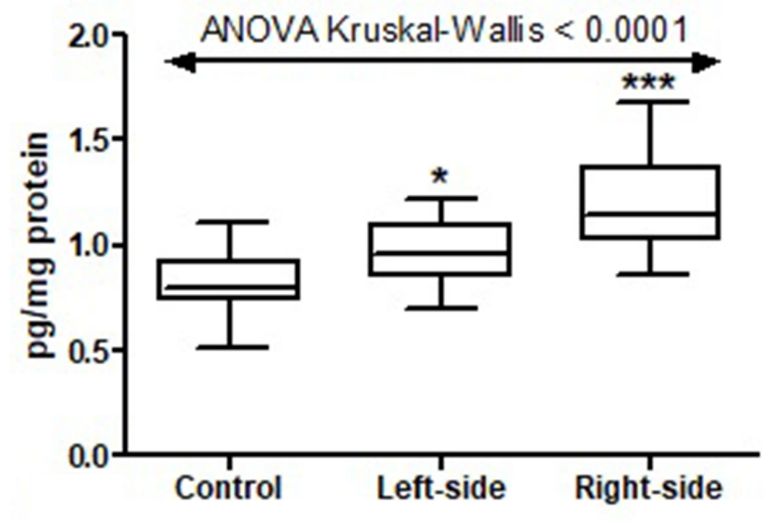

\section{Protein oxidation products}

PC

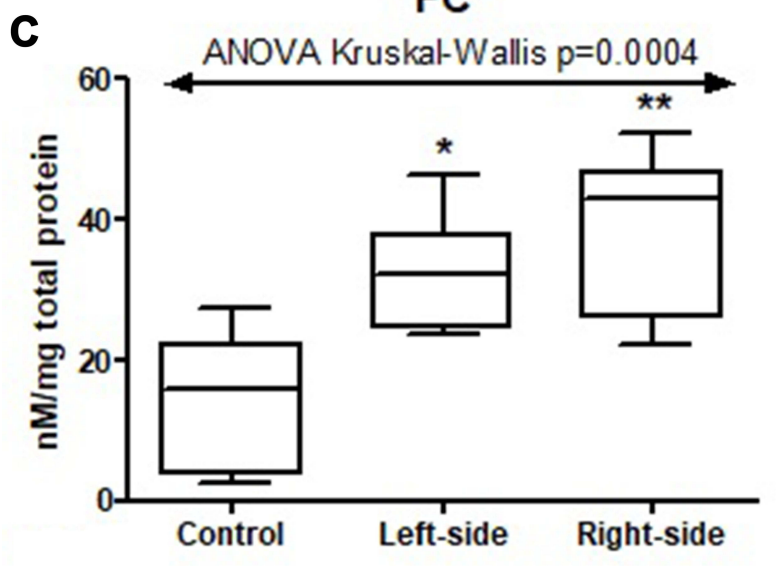

IMA

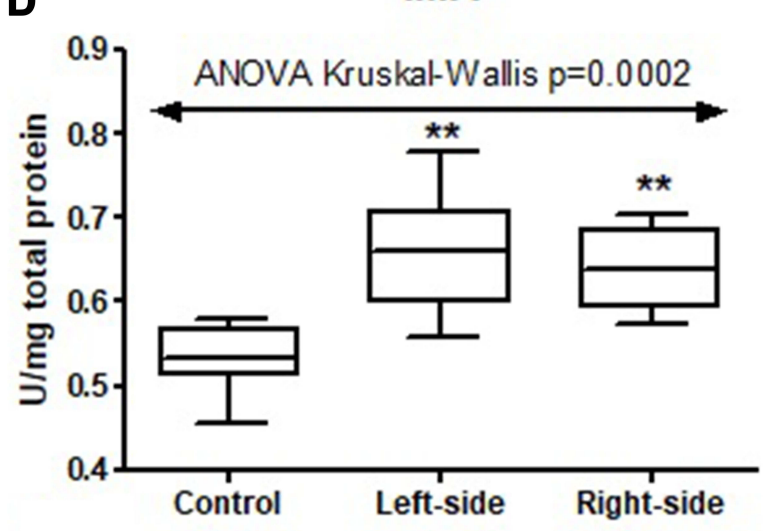

E

Total thiols

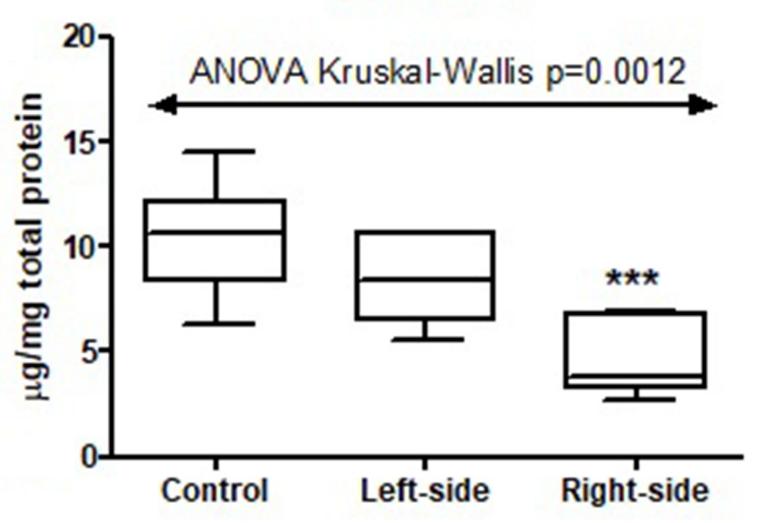

Figure 2 Total antioxidant capacity (FRAP (A)), DNA (8-OHdG (B)) and protein oxidation products (PC (C), IMA (D) and total thiols (E)) in tumours located in the leftside and right-side of the colon and normal mucosa. The data are presented as median (minimum - maximum). ${ }^{*} p<0.05$, $* * P<0.01$, ${ }^{* * *} p<0.00 \mathrm{I}$.

Abbreviations: FRAP, ferric reducing antioxidant power; 8-OHdG, 8-hydroxydeoxyguanosine; PC, protein carbonyls; IMA, ischemia modified albumin. 
described as the presence of tumour cells within the perineural space or in direct contact with nerve fascicles (Figure 1B). ${ }^{30}$

Detailed characteristics of the study groups are summarised in Table 1.

\section{Total Antioxidant Capacity}

In order to assess the total antioxidant capacity, we determined the ferric reducing antioxidant power - FRAP. FRAP level was significantly higher in colorectal cancer tissue than normal mucosa $(\mathrm{p}=0.0032)$ (Table S1). Moreover, the FRAP level increased in the left-side tumour compared to the right-side tumour and normal mucosa $(\mathrm{p}=0.0009)$ (Figure 2 and Table S2$)$.

\section{Protein Oxidation}

We measured the concentration of protein oxidation products: protein carbonyls (PC), total thiols, and ischemia modified albumin (IMA). We demonstrated considerably higher levels of PC and IMA, whereas total thiol concentration was considerably lower in colorectal cancer tissue compared to normal mucosa $(\mathrm{p}<0.0001, \mathrm{p}=0.0007$, $\mathrm{p}<0.0001$, respectively) (Table S1). The PC level was higher in the right-side tumour $(\mathrm{p}=0.0004)$ and IMA in the left-side tumour $(\mathrm{p}=0.0002)$ compared to the other groups (Figure 2 and Table S2). We also observed a significantly higher total thiol concentration in the rightside tumour than the left-side $(\mathrm{p}=0.0222)$ (Figure 2 and Table S2). Total thiol concentration was also significantly higher in mucinous adenocarcinoma than adenocarcinoma $(\mathrm{p}=0.0010) \quad$ (Figure 3 and Table S2). We observed increased PC concentration in tumour tissue in stage T3 compared to T2 $(\mathrm{p}=0.0077)$ (Figure 3 and Table S2). PC concentration was higher in patients with vascular invasion compared to those without the invasion $(\mathrm{p}=0.01)$ and in patients with moderate and strong inflammatory infiltration in the tumour center compared to absent and weak inflammatory infiltration $(\mathrm{p}=0.0276)$ (Figures 4 and 5, Table S2).

\section{Protein Glycoxidation}

We also evaluated concentration of tryptophan, kynurenine, $\mathrm{N}$-formylkynurenine, dityrosine, Amadori product and AGE, which are protein glycooxidation products. Generally, the fluorescence of these substances (tryptophan, kynurenine, N-formylkynurenine, dityrosine, Amadori product, AGE) was significantly higher in colorectal cancer tissue in comparison with normal mucosa $(p<0.0001$, $\mathrm{p}<0.0001, \mathrm{p}<0.0001, \mathrm{p}<0.0001, \mathrm{p}=0.0038$ and $\mathrm{p}<0.0001$, respectively) (Table S1). Tryptophan level was considerably lower in left-side tumour than in control, whereas levels of kynurenine, N-formylkynurenine, dityrosine, Amadori product, and AGE were significantly increased in both left- and right-side tumour in comparison with control (Figure 6 and Table S2). AGE concentration was higher in patients with adenocarcinoma and in patients with distant metastasis $(\mathrm{p}=0.046, \mathrm{p}=0.02)$ (Figure 3 and Table S2). In patients with vascular invasion, tryptophan concentration was lower, whereas Amadori product and AGE were higher than in the group without invasion $(\mathrm{p}=0.0005, \mathrm{p}=0.0449$, $\mathrm{p}=0.0057$, respectively) (Figure 4 and Table S2). Kynurenine, dityrosine and AGE level was higher in the group of patients with neural invasion $(\mathrm{p}=0.0259, \mathrm{p}=0.038$, $\mathrm{p}=0.0093$, respectively) (Figure 7 and Table S2). We also observed statistically significant differences in tryptophan and Amadori product concentration between absent and weak versus moderate and strong inflammatory infiltration in the invasive front $(\mathrm{p}=0.0043, \mathrm{p}=0.0386$, respectively) as well as in tryptophan level between absent and weak versus moderate and strong inflammatory infiltration in the tumour center $(\mathrm{p}=0.0476)$ (Figure 5 and Table S2). Amadori products level was significantly higher $(\mathrm{p}=0.0095)$ in patients with intermediate and high budding than in low budding (Figure 7 and Table S2).

\section{DNA Oxidation Products}

We assessed oxidative stress using products of oxidative damage to DNA - 8-hydroxydeoxyguanosine (8-OHdG). There was a statistically significant increase in $8-\mathrm{OHdG}$ concentration in colorectal cancer tissue compared to the normal mucosa $(\mathrm{p}<0.001)$ (Table S1). Furthermore, 8 -OHdG concentration was significantly higher in the right-side tumour than in left-side $(\mathrm{p}=0.0099)$ (Figure 2 and Table S2). 8-OHdG level was lower in patients with mucinous adenocarcinoma than in those with adenocarcinoma $(\mathrm{p}<0.05)$ (Figure 3 and Table S2).

\section{Nitrosative Stress}

In order to evaluate nitrosative stress, we analysed MPO activity and concentrations of NO, peroxynitrite, and nitrotyrosine. The activity of MPO and concentrations of NO, peroxynitrite, and nitrotyrosine were considerably higher in colorectal cancer tissue than in normal mucosa $(p<0.0001$, $\mathrm{p}<0.0001, \mathrm{p}<0.0009, \mathrm{p}=0.0004$, respectively) (Table S1). The differences in MPO activity as well as NO, peroxynitrite, and nitrotyrosine concentrations between left-side, right-side 
A

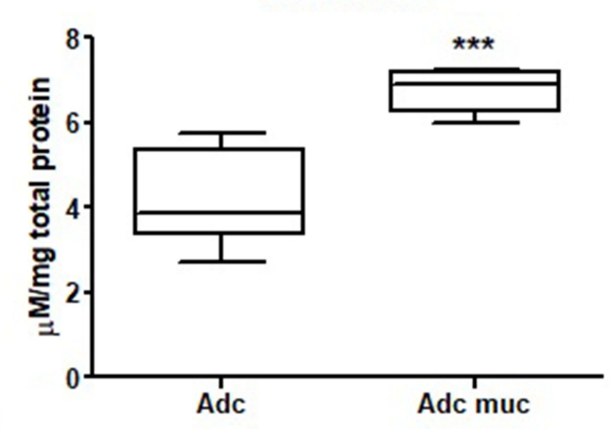

C

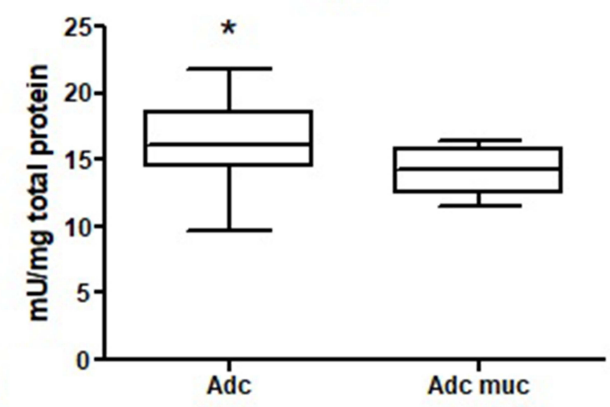

$\mathbf{E}$

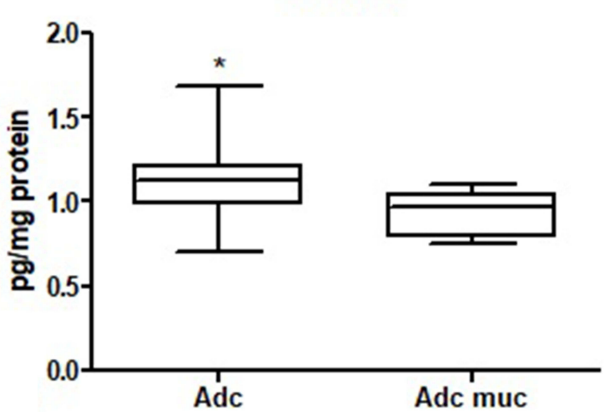

G

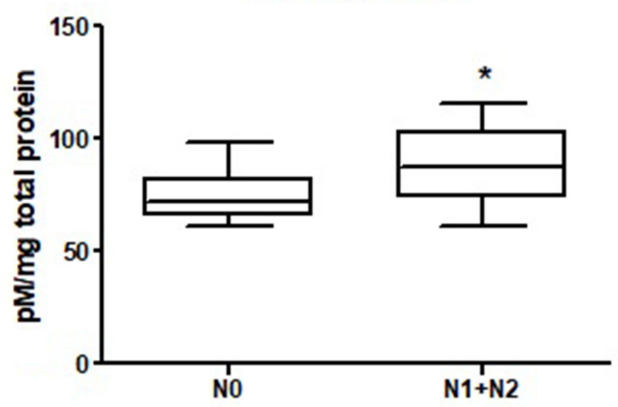

B

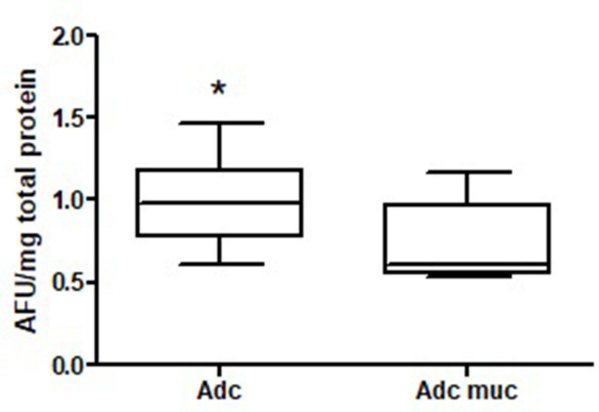

D Nitroty rosine

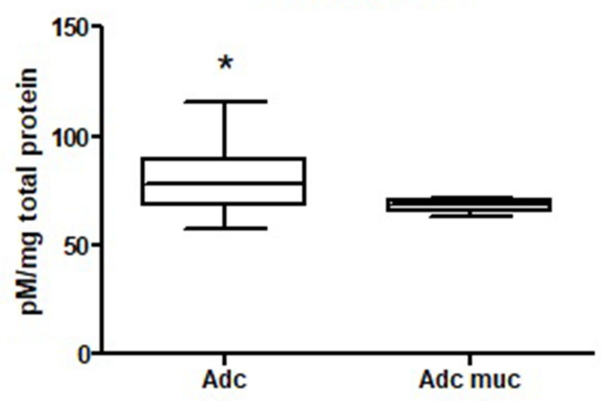

$\mathbf{F}$

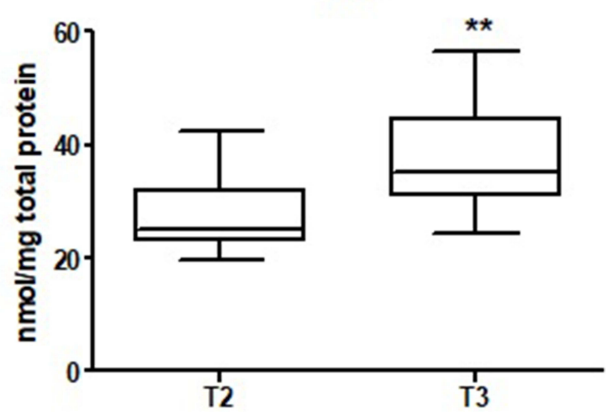

H

AGE

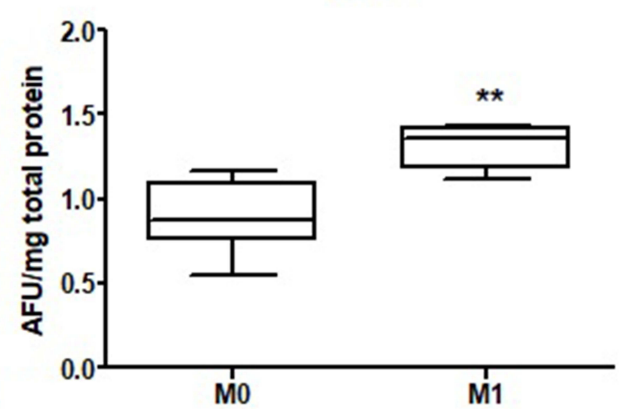

Figure 3 Comparison of: total thiols (A), AGE (B), MPO (C), nitrotyrosine (D), 8-OHdG (E) activity between adenocarcinoma and mucinous adenocarcinoma; PC concentration between T2 and T3 stage (F), nitrotyrosine level between group with and without lymph node metastasis (G) and AGE level in group with and without distant metastasis $(\mathbf{H})$. The data are presented as median (minimum - maximum). ${ }^{*} p<0.05$, ${ }^{* *} p<0.01$, $* * * p<0.001$.

Abbreviations: AGE, advanced glycation end products; MPO, myeloperoxidase; 8-OHdG, 8-hydroxydeoxyguanosine; PC, protein carbonyls. 
A

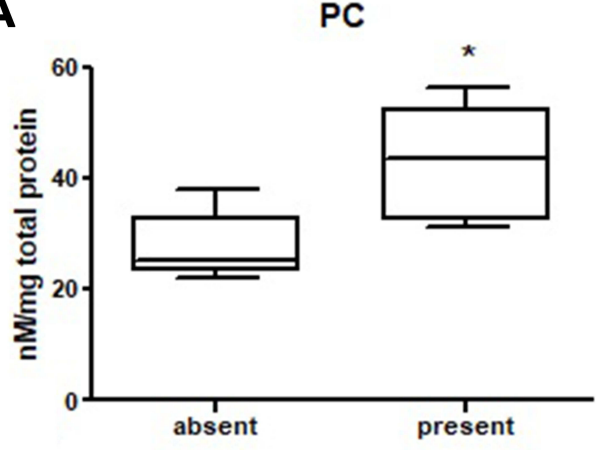

C

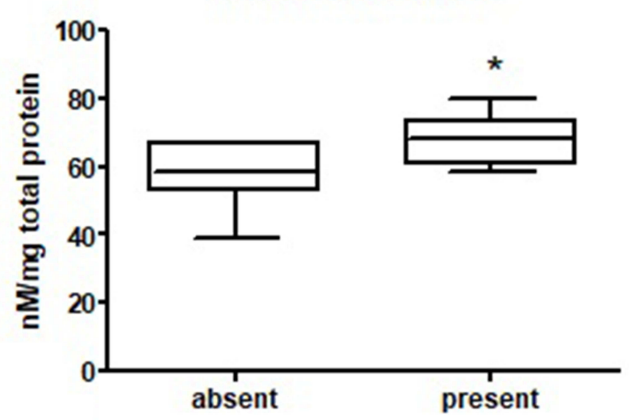

$\mathbf{E}$

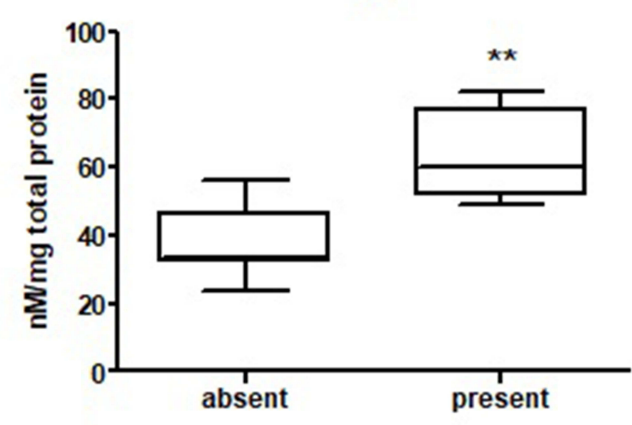

B

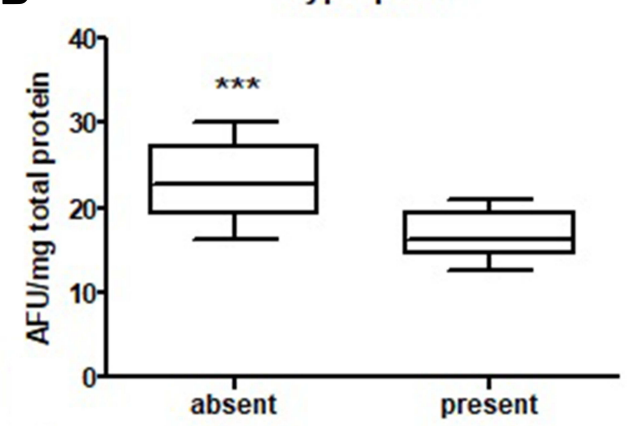

D

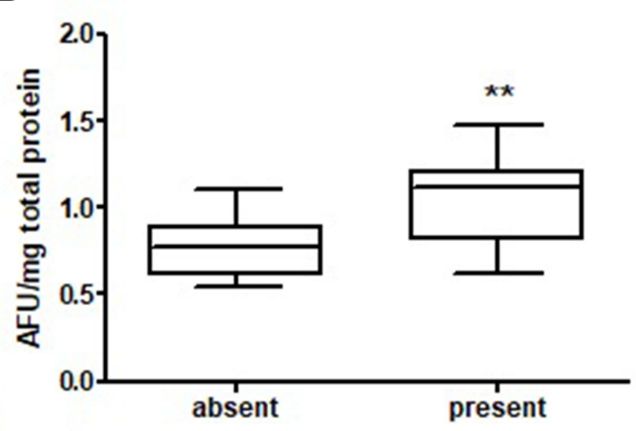

$\mathbf{F}$

Peroxy nitrite

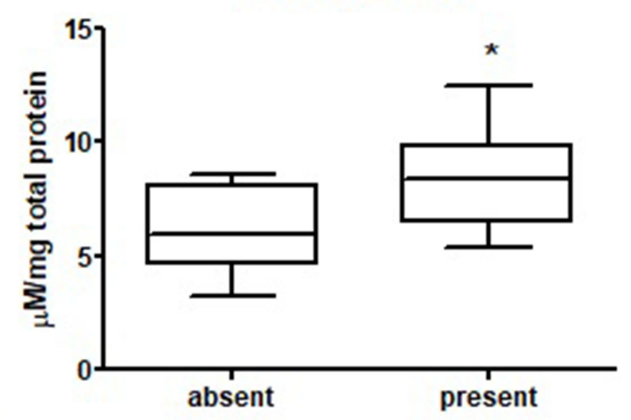

G

Nitroty rosine

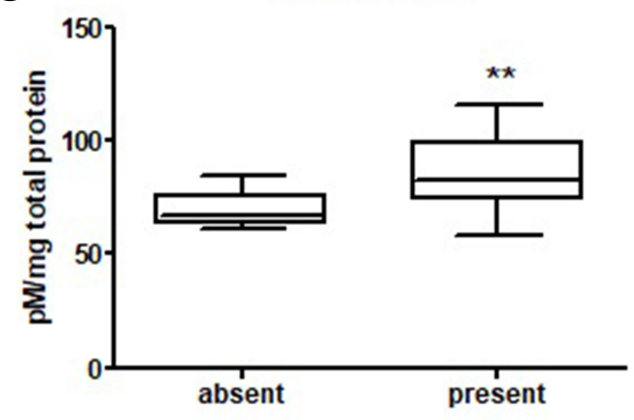

Figure 4 Comparison of: PC (A), tryptophan (B),Amadori products (C), AGE (D), NO (E), peroxynitrite (F) and nitrotyrosine (G) level between tumours with present and absent vascular invasion. The data are presented as median (minimum - maximum). $* \mathrm{p}<0.05,{ }^{* *} \mathrm{p}<0.0 \mathrm{I}, * * * \mathrm{p}<0.00 \mathrm{I}$.

Abbreviations: PC, protein carbonyls; AGE, advanced glycation end products; NO - nitric oxide. 

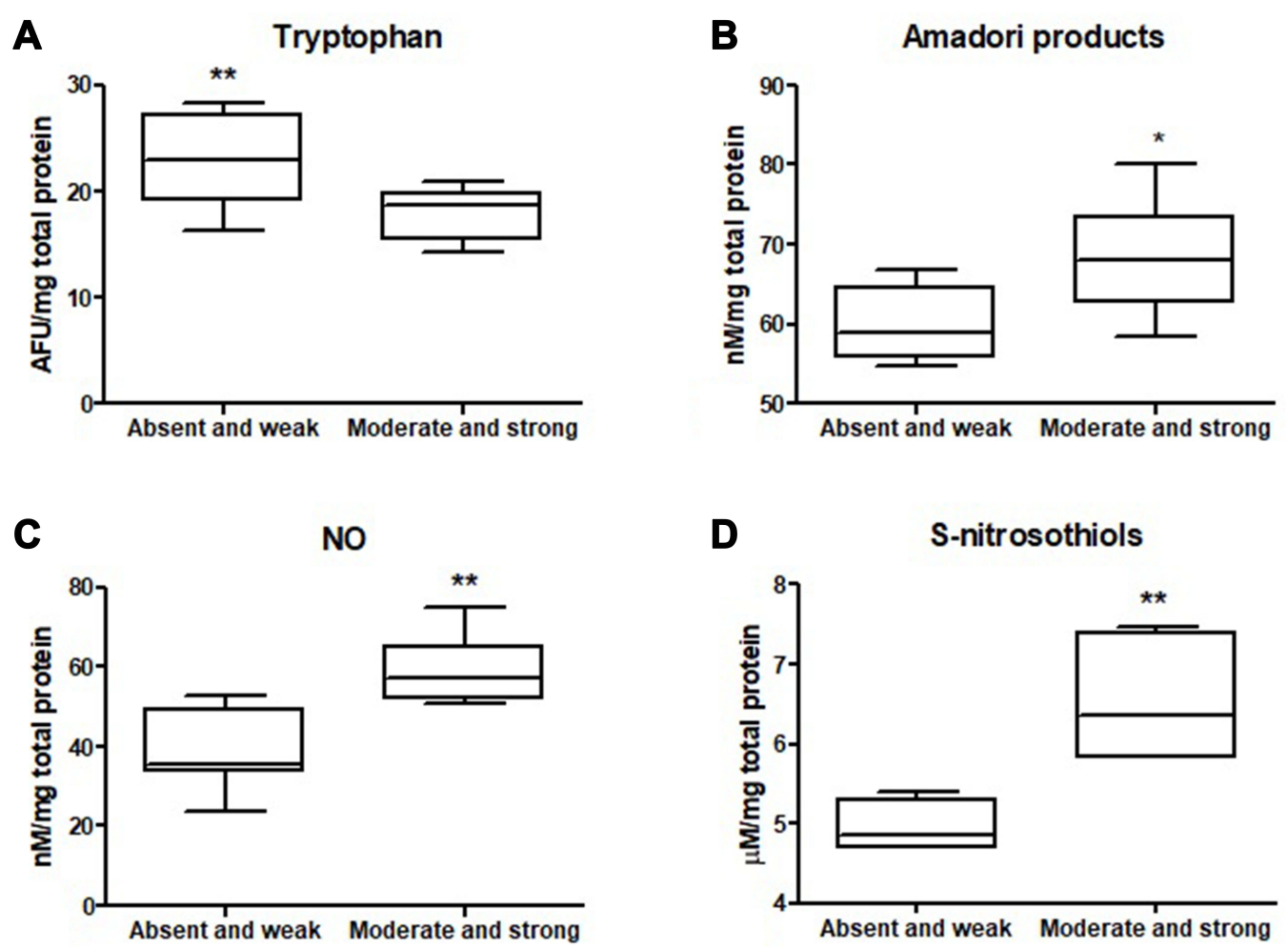

D
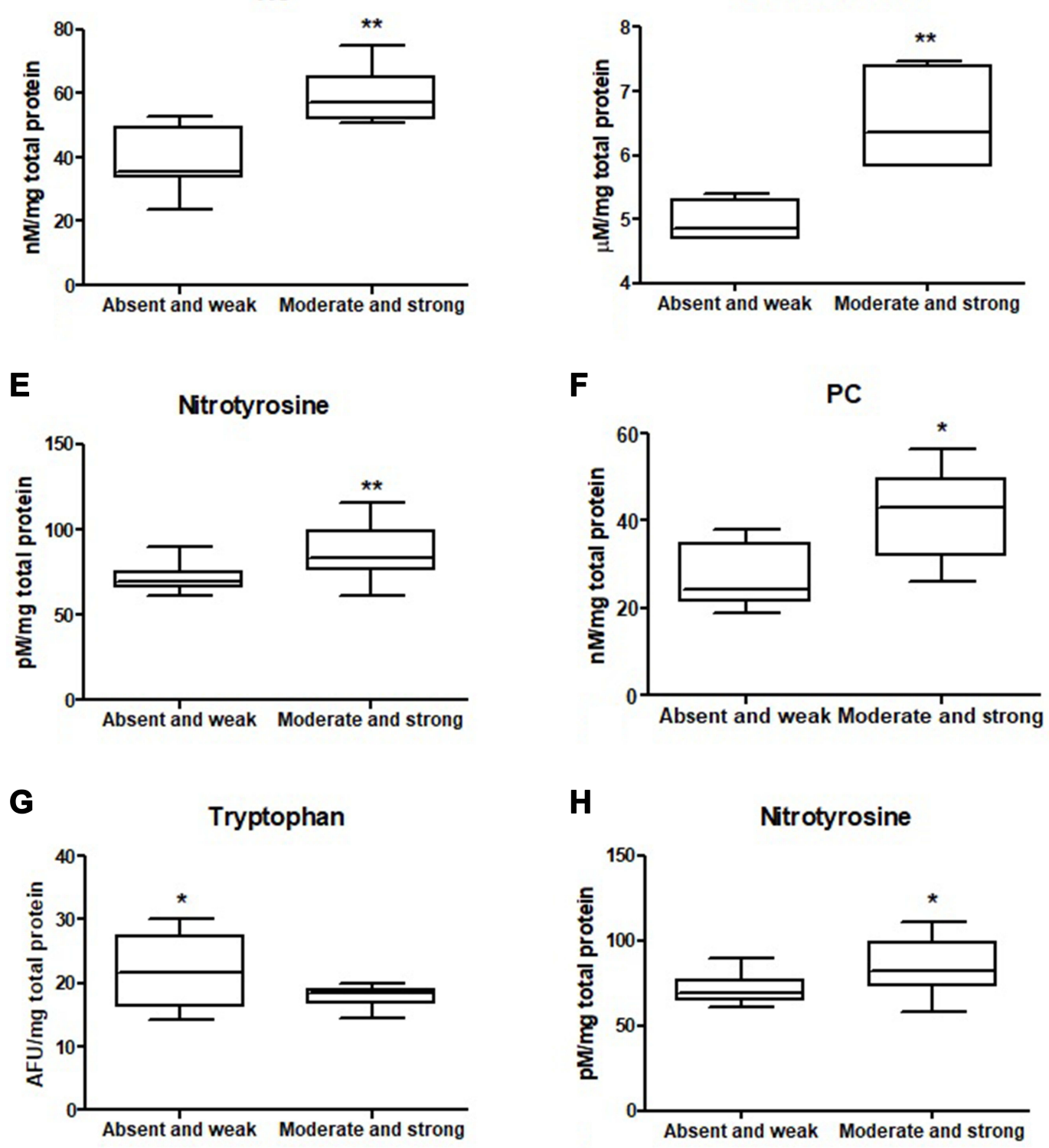

Figure 5 Comparison of: tryptophan (A), Amadori products (B), NO (C), S-nitrosothiols (D) and nitrotyrosine (E) level between tumours with absent and weak and moderate and strong inflammatory infiltration in the invasive front and comparison of: PC $(\mathbf{F})$, tryptophan $(\mathbf{G})$ and nitrotyrosine $(\mathbf{H})$ level between tumours with absent and weak and moderate and strong inflammatory infiltration in the tumour center. The data are presented as median (minimum - maximum). $*_{\mathrm{p}}<0.05$, $* * \mathrm{p}<0.01$. Abbreviations: NO, nitric oxide; PC, protein carbonyls. 


\section{Protein glycooxidation products}

A

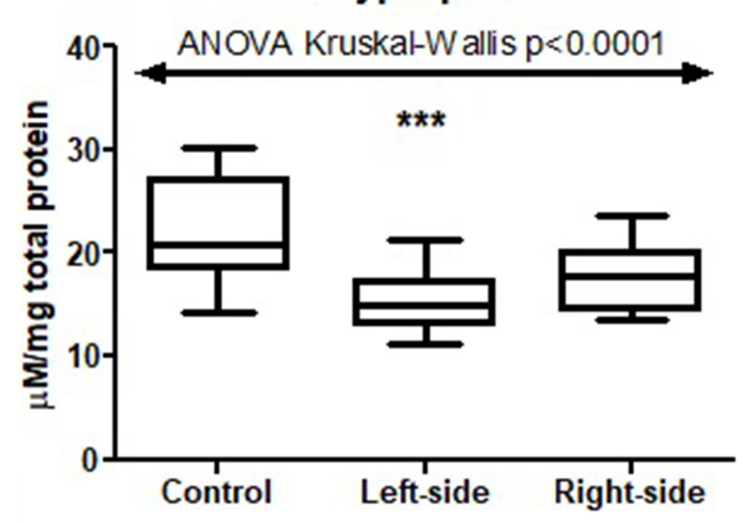

C

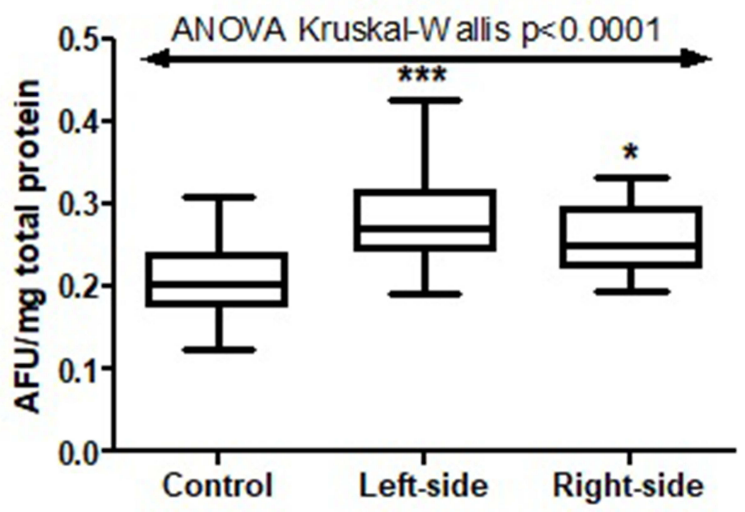

E Amadori products

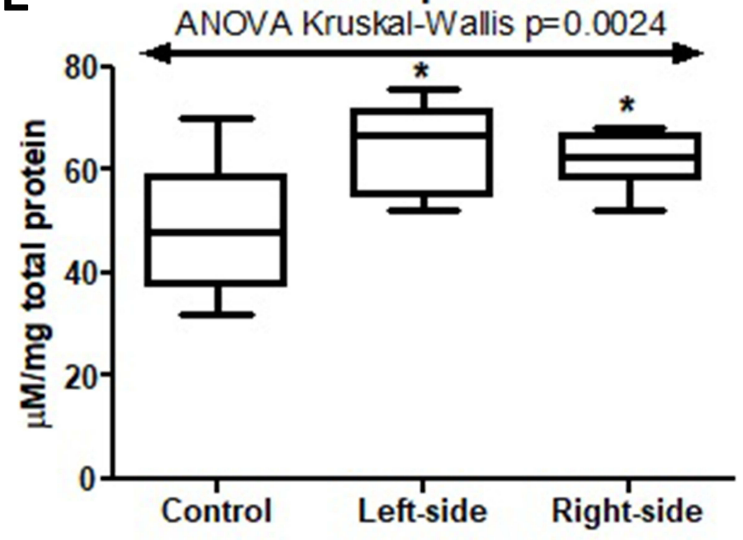

B

Kynurenine

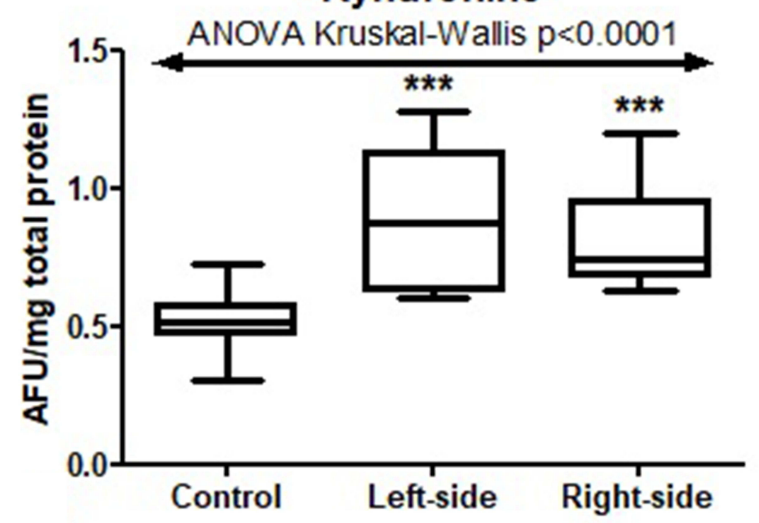

D

Dityrosine

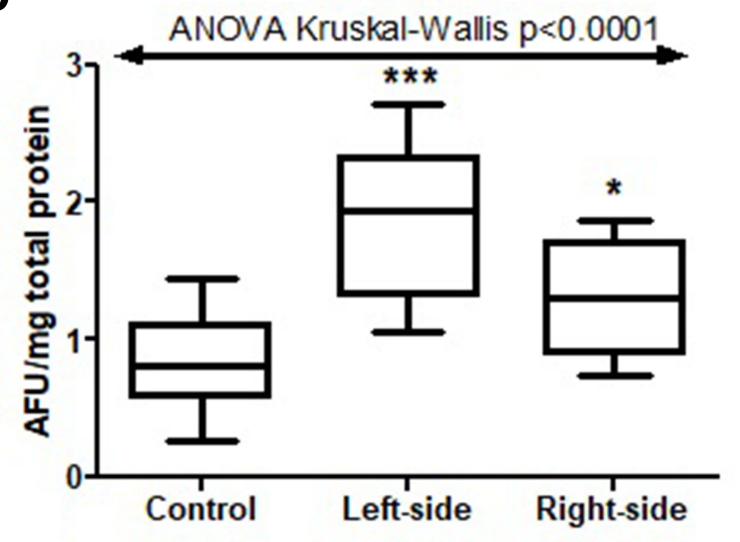

$\mathbf{F}$

AGE

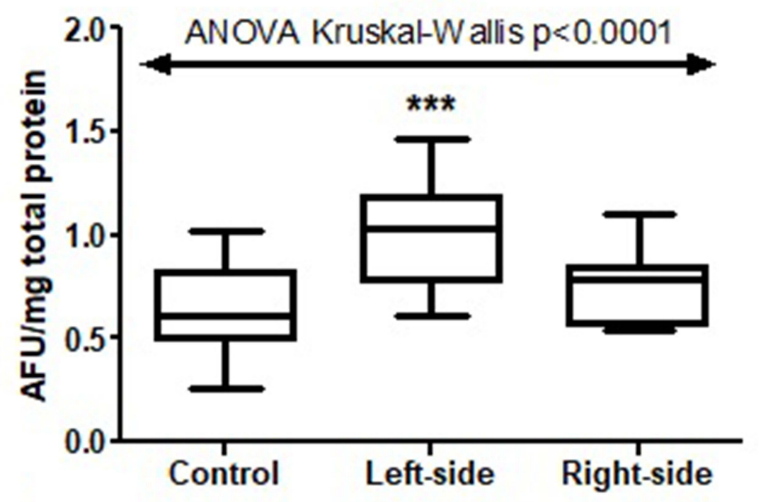

Figure 6 Protein glycooxidation products (tryptophan (A), kynurenine (B), N-formylkynurenine (C), dityrosine (D), Amadori products (E), AGE (F)) in tumours located in the left-side and right-side of the colon and normal mucosa. The data are presented as median (minimum - maximum). $* \mathrm{p}<0.05, * * * \mathrm{P}<0.00 \mathrm{I}$.

Abbreviation: AGE, advanced glycation end products. 

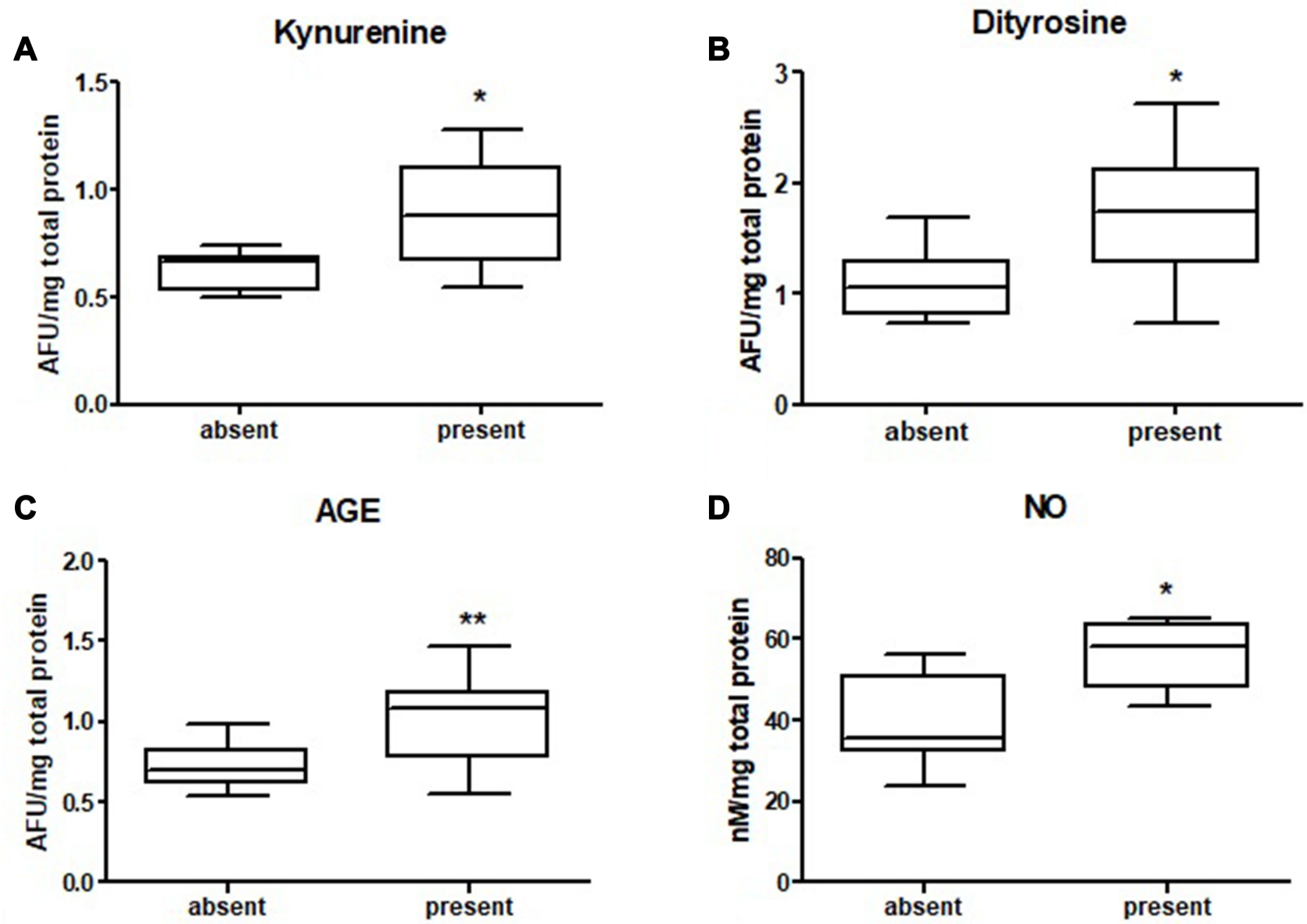

D

NO
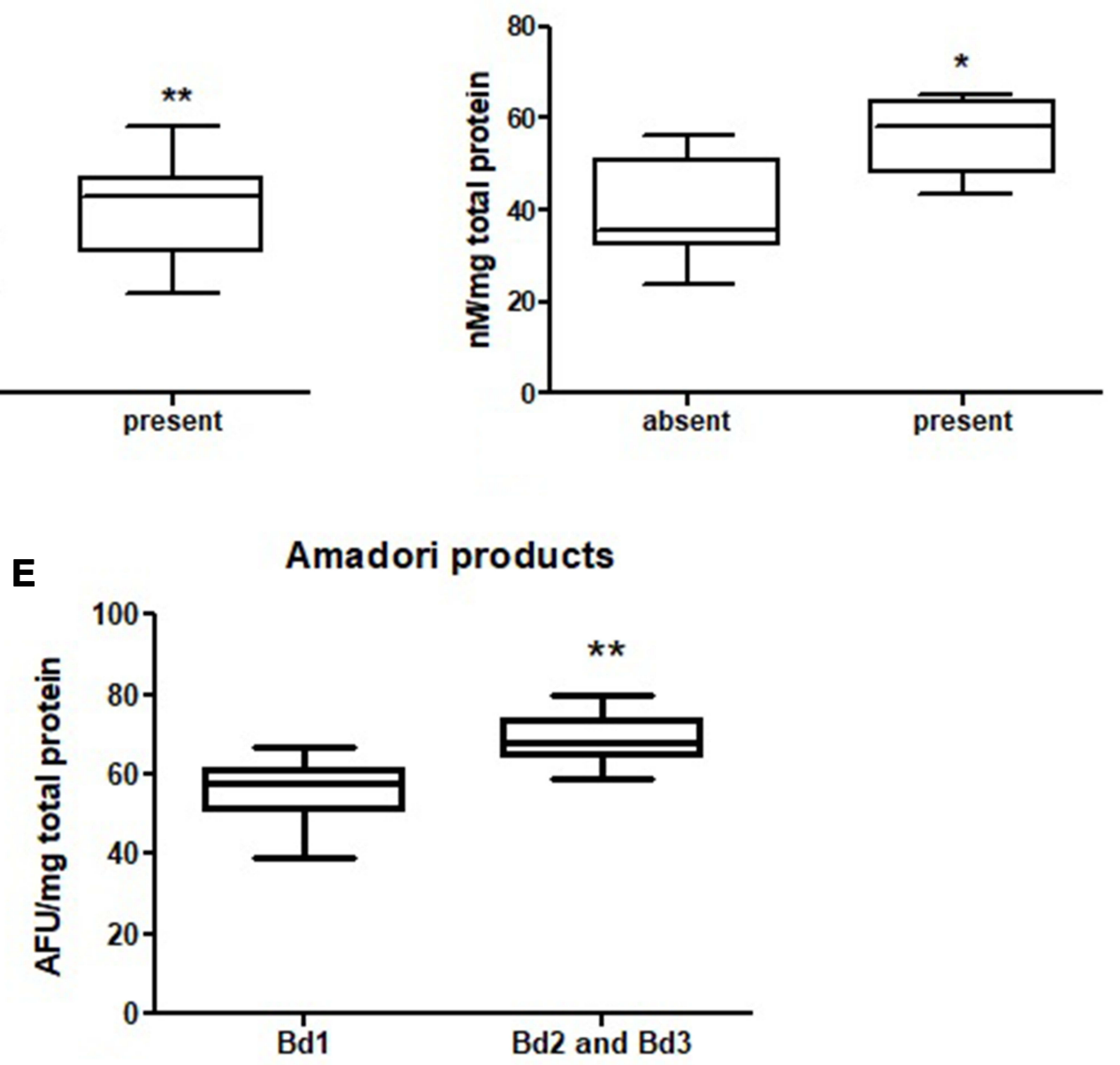

Figure 7 Comparison of: kynurenine (A), dityrosine (B), AGE (C) and NO (D) level between tumours with present and absent neural invasion and Amadori products level (E) between tumours with low budding $(\mathrm{BdI})$ and intermediate and high budding ( $\mathrm{Bd} 2$ and 3 ). The data are presented as median (minimum - maximum). ${ }^{*} \mathrm{p}<0.05$, ** $\mathrm{p}<$ 0.01.

Abbreviations: AGE, advanced glycation end products; NO, nitric oxide. 


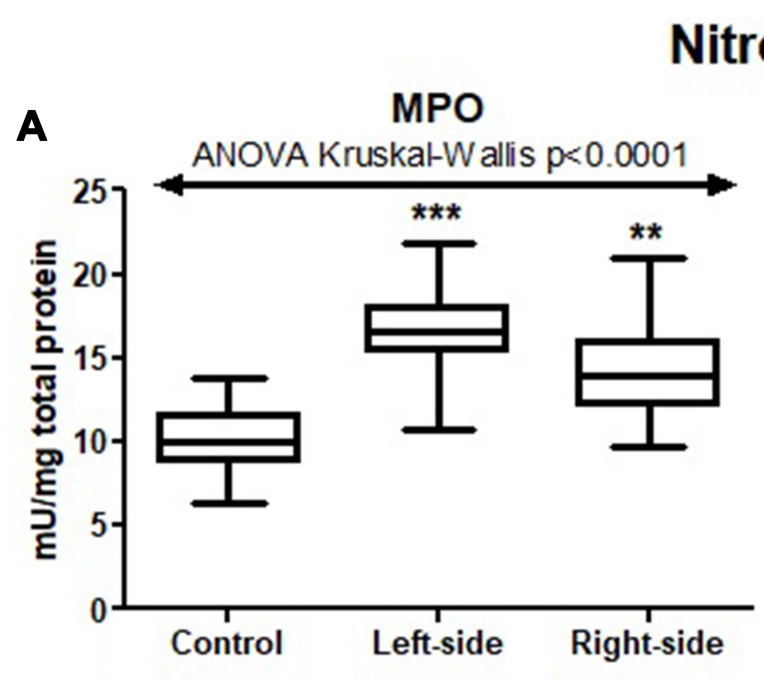

B

NO

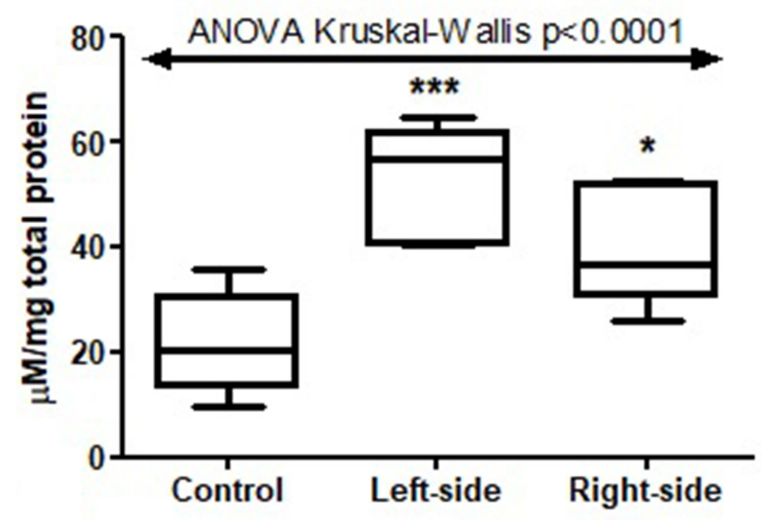

C

Peroxynitrite

D

S-nitrosothiols
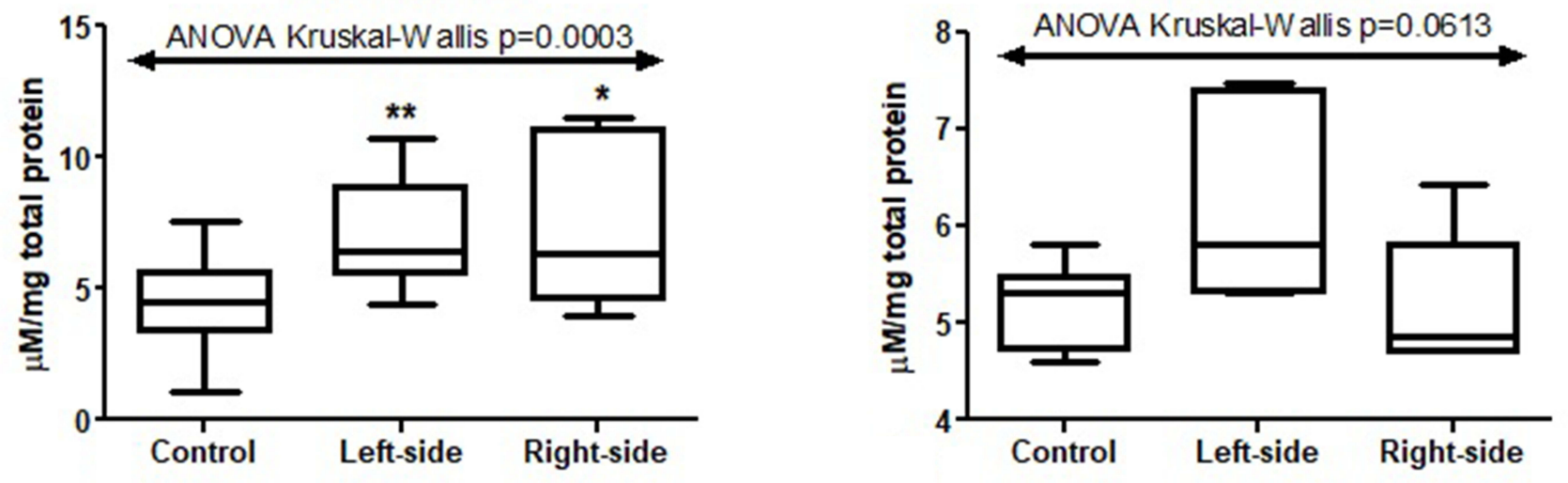

E

Nitrotyrosine

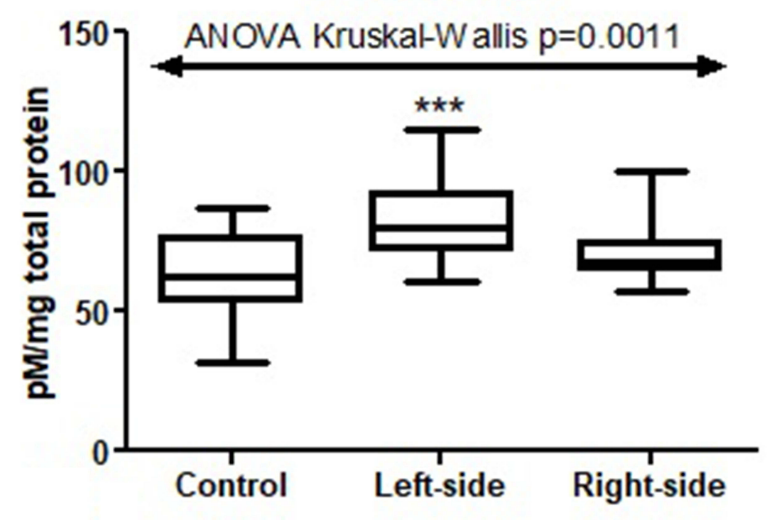

Figure 8 Nitrosative stress parameters (MPO (A), NO (B), peroxynitrite (C), S-nitrosothiols (D), nitrotyrosine (E)) in tumours located in the left-side and right-side of the colon and normal mucosa. The data are presented as median (minimum - maximum). $* \mathrm{p}<0.05, * * \mathrm{p}<0.0 \mathrm{I}, * * * \mathrm{p}<0.00 \mathrm{I}$.

Abbreviations: MPO, myeloperoxidase; NO, nitric oxide. 


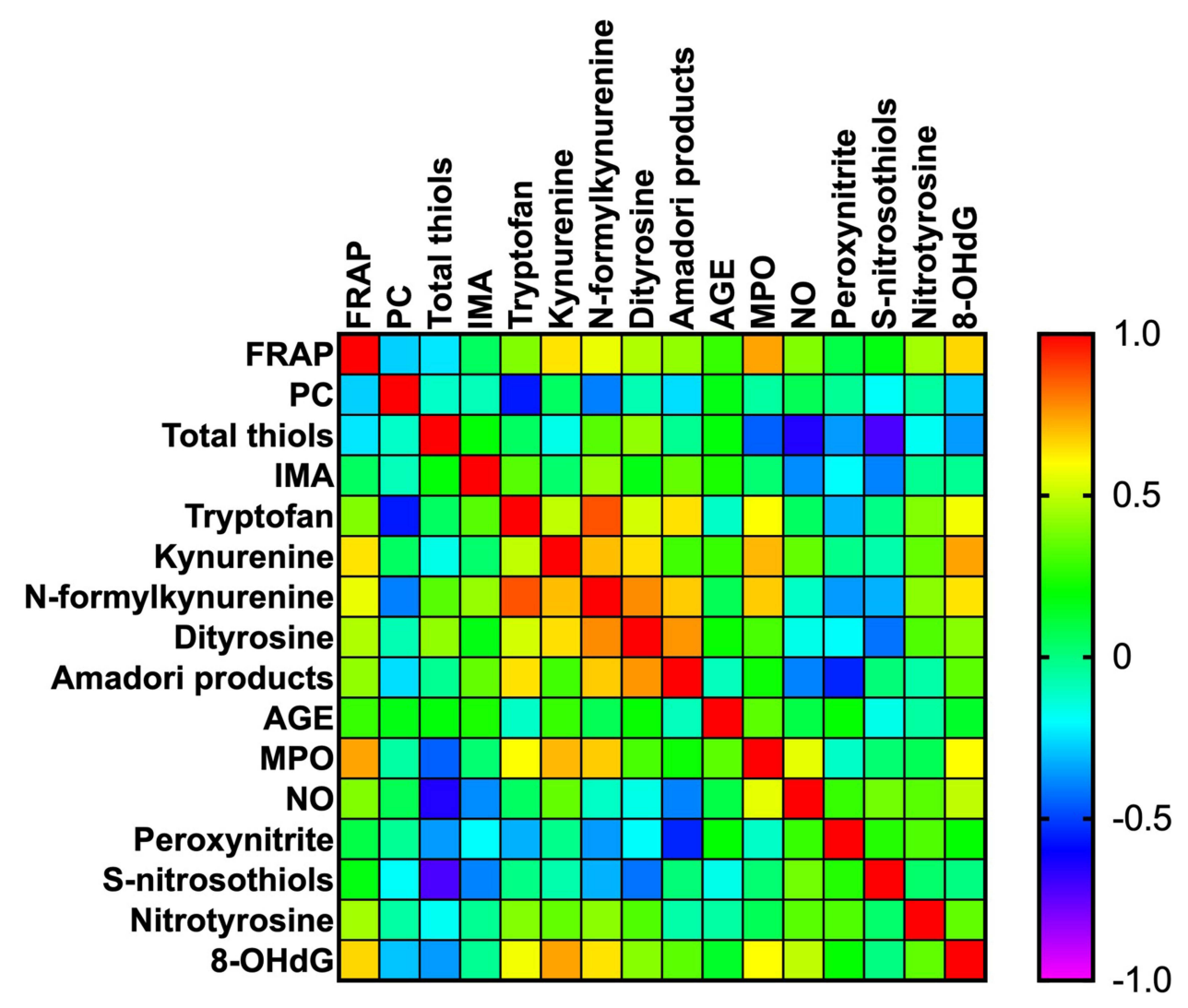

Figure 9 Heat map of oxidative stress parameters in the tumour tissue.

tumours, and control were also statistically significant $(\mathrm{p}<0.0001, \mathrm{p}<0.0001, \mathrm{p}=0.0003, \mathrm{p}=0.0011$, respectively) (Figure 8 and Table S2).

\section{Correlations}

All statistically significant correlations between total antioxidant capacity, protein/DNA oxidation, glycoxidation products, and nitrosative stress parameters are presented in Figure 9. Interestingly, we observed a positive correlation between dityrosine and FRAP $(p=0.042, R=0.374)$ and dityrosine and $\mathrm{N}$-formylkynurenine $(\mathrm{p}<0.0001$, $\mathrm{R}=0.612$ ). We also demonstrated correlations between MPO and AGE $(p=0.05, \quad R=0.358), \quad$ MPO and S-nitrosothiols $(\mathrm{p}=0.040, \mathrm{R}=-0.377)$ and $\mathrm{MPO}$ and $\mathrm{N}$-formylkynurenine $(\mathrm{p}=0.015, \mathrm{R}=0.438)$. Moreover, statistically significant correlations were found between kynurenine and tryptophan $(\mathrm{p}=0.05, \mathrm{R}=0.361)$ and peroxynitrite and AGE $(\mathrm{p}=0.027, \mathrm{R}=0.403)$. Correlations between oxidative and nitrosative stress parameters and clinicopathological features have been shown in Figure S1.

\section{Discussion}

It is well known that redox imbalance is associated with malignant transformation. It has been observed that cancer cells produce an abundant amount of ROS/RNS and it may be a consequence of enhanced basal metabolic activity, mitochondrial dysfunction caused by hypoxia or mitophagy, uncontrolled cytokine signalling, oncogene and peroxisome activity, as well as enhanced activity of lipoxygenase (LOX), cyclooxygenase (COX), NADPH oxidase (NOX), nitric oxide synthase (NOS), xanthine oxidoreductase or cytochrome c oxidase. ${ }^{31}$ If ROS and RNS overproduction is not counterbalanced by antioxidants, then the oxidative and nitrosative damages to proteins, lipids, and nucleic acids occur. ${ }^{33}$ It has been confirmed that some of the human cancers, including ovarian, breast, bladder, prostate, oral, pharyngeal, hepatic and gastric cancers, can generate much more amount of reactive oxygen and nitrogen species in vitro and have decreased antioxidant barrier activity as compared with non-cancerous cells. ${ }^{32}$ 


\section{Total Antioxidant Capacity}

In this paper, we assessed the total antioxidant capacity reflecting the total content of all antioxidants. Diagnostic value of this biomarker is higher than the evaluation of each antioxidant separately. The total antioxidant potential, also described as "total antiradical activity," defines the biological system's general capability to scavenge oxygen and nitrogen-free radicals. ${ }^{34}$ In this study, we determined one of the most common parameters for measuring the total antioxidant activity - FRAP. FRAP measurement is based on the reduction reaction of $\mathrm{Fe}^{3+}$ to $\mathrm{Fe}^{2+}$ in the presence of antioxidant enzymes, which are reductants with half-reaction reduction potentials above $\mathrm{Fe}^{3+} / \mathrm{Fe}^{2+} .{ }^{18}$ FRAP level mainly depends on the uric acid level (about $60 \%$ ) as well as other antioxidants with low molecular weight-like vitamin C (15\%), $\alpha$-tocopherol (5\%), protein (10\%), and bilirubin (5\%), respectively. ${ }^{18}$ In this study, we demonstrated significantly higher FRAP level in tumour than non-tumour tissue, which may be the adaptative response for intensive ROS/RNS production by cancer cells. FRAP level was also increased in right-sided tumours compared to left-side. The differences in FRAP level may be caused by different molecular pathways involved in cancer development located in both sides of the colon, tumour size and malignancy grade. The rightside tumour is usually larger and characterized by higher malignancy grade than left-side tumour.

\section{Protein Oxidation Products}

Disturbances in ROS and RNS production and efficiency of antioxidant barrier lead to oxidative damage to proteins, lipids, and DNA bases. Proteins are the basic elements of the cell. Therefore, they are the main goal of action of oxygen-free radicals. ${ }^{35}$ Oxidative damage to proteins including nitration of aromatic amino acid, oxidation of thiol groups, or breaking of polypeptide chains with simultaneous formation of cross-links may be considered as biomarkers of oxidative stress intensity. ${ }^{36}$ In this paper, we observed an increased level of oxidative protein modifications (protein carbonyls, IMA, total thiols) and glycoxidation (kynurenine, N-formylkynurenine, dityrosine, Amadori product, AGE) in colorectal cancer tissue compared to healthy colon tissue. The most widely used biomarkers for the measurement of protein oxidation are protein carbonyls. PC are formed when ROS and RNS attack the amino acid side chains of arginine, cysteine, histidine, proline, threonine or lysine, in the presence of metal ions $-\mathrm{Fe}^{2+}, \mathrm{Cu}^{2+}$, etc. ${ }^{37} \mathrm{PC}$ may also be generated in "secondary protein carbonylation," in which compounds having reactive carbonyl groups (lipids, carbohydrates) bind to amino acid side chains (primarily on cysteine, histidine and lysine residues). ${ }^{38}$ Protein carbonyls belong to the group of irreversible protein oxidative modifications, and their accumulation is often observed in the course of different diseases, eg, rheumatoid arthritis, muscular dystrophy, Alzheimer's disease, or respiratory distress syndrome, ${ }^{39}$ as well as in some types of cancers Hodgkin's lymphoma, ${ }^{40}$ bladder, ${ }^{41}$ prostate ${ }^{42}$ and breast cancer. ${ }^{43}$ In our work, we showed a considerably higher level of PC in colon cancer tissue than normal mucosa, which confirms that the accumulation of damaged proteins may be associated with malignant transformation. PC level was also higher in tumours in the T3 stage compared to T2. On the basis of our observations, we may conclude that the accumulation of protein carbonyls increases with tumour invasion depth (pT) and, consequently, cancer progression. Indeed, $\mathrm{pT}$ is one of the basic diagnostic parameters used to assess cancer advancement. The other tumour advancement indicators are vascular and neural invasion. In our paper, PC level was increased in patients with a vascular invasion than in those without an invasion. It also confirms that PC concentration increases with CRC progression and therefore, total carbonyls may be a potential biomarker of CRC advancement. We also demonstrated a higher PC level in tumour with a moderate and strong inflammatory infiltration than cancer without/weak infiltration. It has been observed that a cascade of inflammatory cells such as neutrophils adhering to cell vasculature may disrupt their barrier. This facilitates for inflammatory cells to infiltrate the interstitial space and result in the release of oxidants and proteases responsible for tissue injury, remodeling, and dysplasia development. ROS, RNS, and cytokines, eg, TNF- $\alpha$ activate nuclear factor kappa-B (NFKB), which prompts the expression of genes taking part in cell apoptosis, proliferation, and carcinogenesis ${ }^{23}$ and also stimulates the production of proinflammatory cytokines. ${ }^{44}$ The effect of inflammatory response is overproduction of reactive oxygen and nitrogen species, which may directly or indirectly cause oxidative cell damage. ${ }^{45}$ The other products of protein oxidation are total thiols and IMA. In this work, we observed a higher concentration of IMA in tumour than non-tumour tissue, whereas total thiols level was decreased in cancerous tissue compared with normal mucosa. Thiols are organic compounds containing the 
sulphydryl groups belonging to the antioxidant barrier and prevent cells from oxidative stress. Therefore, the decreased level of thiol groups can be associated with lower serum antioxidant power.

\section{Protein Glycooxidation Products}

Aromatic amino acids are very sensitive to oxidative damage, as confirmed by the results of our study. We demonstrated quenching of tryptophan fluorescence and an increase level of protein glycoxidation products (kynurenine, N-formylkynurenine, dityrosine, Amadori products, and AGE) in colorectal cancer tissue in comparison with normal mucosa. The difference in tryptophan fluorescence between cancerous and non-cancerous tissue indicates the rapid catabolism of tryptophan in tumours, with a possible accumulation of subsequent products N-formylkynurenine and kynurenine. ${ }^{46}$ It has been observed that colorectal cancer cells are characterized by higher metabolic rate of tryptophan in comparison with normal colon cells. The oncogenic transcription factor MYC mediates in this process and promotes the arylformamidase - tryptophan metabolizing enzyme and its importers - SLC1A5 and SLC7A5. As mentioned above, one of the products of tryptophan metabolism in colon cancer cells is kynurenine, a biologically active compound take part in maintaining continuous cell proliferation. Kynurenine may act as an oncometabolite and via the activating the transcription factor $\mathrm{AhR}$ take part in the process of regulating growth-promoting genes in cancer cells. ${ }^{47}$ Recent reports indicate that inhibition of kynurenine activity may reduce the growth of cancer cells. ${ }^{47}$ Interestingly, tryptophan fluorescence was considerably lower, whereas AGE was higher in tumour on the rightside than the left-side of the colon. The differences may be associated with genetic and epigenetic alterations in tumours. We may conclude that tumour location may influence the hyperactivation of the catabolic pathway of tryptophan and the accumulation of its metabolites. Decreased tryptophan and increased AGE and Amadori products contents were associated with present vascular invasion, whereas fluorescence of kynurenine, dityrosine, and $\mathrm{AGE}$ was higher in $\mathrm{CRC}$ with present neural invasion than in absent neural invasion. AGE can rise as a result of autooxidation of carbohydrates and other glycation intermediates - Amadori product S and Schiff base and bind to receptors for advanced glycation end products (RAGE). AGE-RAGE complex promotes the activation of NADPHoxidase system leading to ROS formation, which further contribute to the activation of the NFאB pathway. The effects of the NFKB activation are following: the overexpression of growth factors, adhesive molecules and cytokines as well as enhanced vascular permeability, and further toxic effects. ${ }^{48,49}$ Therefore, it is not surprising that AGE fluorescence was higher in tumours with vascular invasion because $\mathrm{NF \kappa B}$ stimulates angiogenesis. $\mathrm{NF \kappa B}$ also has been recognized as a significant factor responsible for the growth and morphology of neural processes in the developing and mature nervous systems. ${ }^{50}$ In pancreatic cancer, inhibition of $\mathrm{NF \kappa B}$ was associated with decreased neural invasion. We may conclude that AGE accumulation in colon cancer cells affects NFKB activation and, consequently, neural invasion. ${ }^{51}$ We observed decreased tryptophan fluorescence in the moderate and strong inflammatory infiltration both in the invasive front and in the tumour center. Simultaneously, there has been a significant increase of Amadori products in moderate and strong inflammatory infiltration in the invasive front compared to absent and weak and high budding compared to low and intermediate budding. It is well known that the accumulation of oxidative protein products lead to chronic inflammation and increased ROS production. ${ }^{12}$ Indeed, Amadori products accumulate and aggregate in cancer tissue, which indirectly increases NADPH oxidase activity and influences (via positive feedback) NFкB expression. ${ }^{52,53}$ The consequence is inflammatory microenvironment growth that influence tumour development through promoting genetic instability, cell survival, growth, and metastatic potential. ${ }^{12}$ The differences in oxidized proteins level may also reflect the rate of protein oxidation and degradation. Oxidatively damaged proteins are not efficiently removed by proteasomes, leading to their accumulation and impaired function in colorectal cancer cells.

\section{DNA Oxidation Products}

We also assessed 8-hydroxydeoxyguanosine considered as a marker of DNA oxidation. 8-hydroxydeoxyguanosine is the most stable and simultaneously most numerous product of oxidative DNA. ${ }^{54}$ We observed an increased level of $8-\mathrm{OHdG}$ in right-side tumours suggesting that DNA repair systems are less effective in the tumour located in right-side of the colon. Tumours in this localization may develop as a consequence of microsatellite instability due to impaired DNA mismatch repair system, which promotes the accumulation of single nucleotide mutations. It has been observed that patients with left-side colorectal cancer 
are characterized by a better overall prognosis than patients with right-side. ${ }^{55}$

\section{Nitrosative Stress}

Cancer cells also produce nitrogen-derived free radicals. One of them is nitric oxide (NO) - a highly reactive compound having ability to react with molecular oxygen, heavy metals and other free radicals. It is generated by nitric oxide synthase (NOS) and has pleiotropic functions. ${ }^{56}$ NO may behave as a messenger molecule and mediated in different processes in human body (macrophage-mediated immunity or neurotransmission. NO via genotoxic and antiapoptotic mechanisms, inhibition of host immune response against cancer, induction of angiogenesis and metastasis, takes part in cancer progression. $^{56}$ It has been observed that NO function may be different in different cancers. ${ }^{57}$ For example, in breast cancer, NO influence tumour blood flow, stimulate angiogenesis, and, consequently, increases malignancy grades. $^{58}$ In gastric cancer, it has been discovered that NO may be engaged in initiation, progression, and metastasis development. ${ }^{59}$ Biological effects of NO may be mediated by the products of its metabolites. Indeed, NO forms other reactive products in the intracellular environment, including nitrite or nitrate, S-nitrosothiols, as well as peroxynitrite. NO also mediates in a reaction called tyrosine nitration, leading to 3-nitrotyrosine (3-NT) formation as a product. The presence of nitrotyrosine in proteins highlights a high intensity of oxidative protein modifications that favor pro-oxidant processes. ${ }^{60}$ So far, the significance of $\mathrm{NO}$ in colorectal carcinogenesis remains unexplained. Therefore, we assessed NO level and other nitrosative stress parameters (peroxynitrite, and nitrotyrosine). We observed that they are significantly increased in colon cancer tissue in comparison with normal mucosa. It is not surprising because cancer cells respond to hypoxia by producing increased NO levels. This may cause the transformation of normal cells into neoplastic cells via numerous molecular events and cellular damages such as DNA damage or genome instability modifying tumour microenvironment or disturbances in cell signalling. ${ }^{32}$ We also reported the differences in S-nitrosothiols and nitrotyrosine levels between tumour located on the left side and on the right side of the colon, indicating that in right-side tumours NO production and consequently the formation of its metabolites is increased. NO, peroxynitrite and nitrotyrosine were also associated with vascular invasion and neural invasion (only NO). It indicates that NO production and formation of its metabolites is higher in advanced tumours that infiltrate vessels and nerves because NO may take part in regulation of cancer cell adhesion to the vascular endothelium (both negatively or positively) due to its concentration in cells, tissues, or at the extracellular space. ${ }^{61} \mathrm{NO}, \mathrm{S}$-nitrosothiols and nitrotyrosine concentration was increased in moderate and strong inflammatory infiltration compared to absent and weak infiltration in the invasive front, whereas nitrotyrosine level was also increased in moderate and strong inflammatory infiltration in the tumour center. Nevertheless, it is not surprising that NO is increased in abundant inflammatory infiltration because inflammatory cells like macrophages or neutrophils are sources of NOS - enzymes responsible for NO production. Recent studies reported that tumours with coexisted chronic inflammation and enhanced production of reactive oxygen and nitrogen species are characterized by increased susceptibility to DNA damage and impaired DNA repair. ${ }^{62}$ In our work, we also assessed myeloperoxidase, which is released by monocytes or neutrophils and during activation of inflammatory cells. MPO is delivered into the extracellular space and the phagosome during neutrophil activation. MPO uses $\mathrm{H}_{2} \mathrm{O}_{2}$ from the neutrophil's oxidative burst and catalyzes hypochlorous acid production $(\mathrm{HOCl})$ and other oxidizing species. $^{63,64}$ In our paper, MPO activity was higher in tumours located on the right-side than on the left-side of the colon and in adenocarcinoma compared to mucinous adenocarcinoma. Higher MPO level may suggest that tumours located in the right side of the colon and adenocarcinomas are characterized by a more intense inflammatory infiltration, especially neutrophils infiltration. In contrast, as observed in a lung carcinogenesis model, inhibition of MPO activity during the early stages of cancer reduced the tumour mass by $50 \%{ }^{65,66}$ These observations confirm that neutrophils and their constituents play a crucial role in tumour formation and metastasis.

\section{Conclusions}

Colorectal cancer development is related to increased oxidative and nitrosative damages to proteins and DNA as well as disturbances in antioxidant defense. We demonstrated differences in nitrosative stress parameters and products of oxidation and glycoxidation of proteins between cancerous and non-cancerous tissue and tumours located in the right and left side of the colon. The assessment of oxidative and nitrosative stress parameters could be helpful for evaluating the progression and 
differentiation of the tumour location. We also showed that redox parameters may depend on histological type of the tumour and may influence tumour invasion depth, presence of lymph node and distant metastasis, vascular and neural invasion, inflammatory infiltration, and tumour budding, which are part of the tumour microenvironment. These parameters are considered as an independent adverse prognostic factors in patients with primary operable colorectal cancer. Therefore, the evaluation of redox parameters may be valuable in prognosis of patients with CRC. However, antioxidant supplementation may support CRC therapies, although this topic requires further research.

Summarizing, it is also worth to take notice of the limitations of our investigation. We performed study on a small group of patients; therefore, further research is needed to perform on a larger group of colorectal cancer patients. We analysed only the selected redox parameters and we cannot fully characterize CRC patients' oxidoreductive balance. In the future, it would be interesting and advisable to evaluate the relationship between the intensity of oxidative and nitrosative stress and the survival rate of patients with $\mathrm{CRC}$.

\section{Abbreviations}

CRC, colorectal cancer; FRAP, ferric reducing antioxidant power; MPO, myeloperoxidase; NO, nitrogen oxide; PC, protein carbonyls; IMA, ischemia modified albumin; AGE, advanced glycation end products; 8-OHdG, 8-hydroxydeoxyguanosine; GLOBOCAN, Global Cancer Observatory; adc, adenocarcinoma; muc adc, mucinous adenocarcinoma; CIN-high, chromosomal instability high; MSI-high, microsatellite instability high; ROS, reactive oxygen species; RNS, reactive nitrogen species; TB, tumour budding; PDC, poorly differentiated clusters; APDC, areas of poorly differentiated components; PBS, phosphate-buffered saline; BHT, butylated hydroxytoluene; TPTZ, 2,4,6-Tri(2-pyridyl)-s-triazine; 2,4-DNPH, 2,4-dinitrophenylhydrazine; HAS, human serum albumin; NBT, nitro blue tetrazolium; FFI, furyl-furanyl-imidazole; CML, carboxymethyl lysine; RCRC, right-side colorectal cancer; LCRC, left-side colorectal cancer; NOX, NADPH oxidase; COX, cyclooxygenase; LOX, lipoxygenase; NOS, nitric oxide synthase; TNF- $\alpha$, tumor necrosis factor- $\alpha$; NFאB, nuclear factor kappa-B; RAGE, receptors for advanced glycation end products; 3-NT, 3-nitrotyrosine; HOCL, hypochlorous acid.

\section{Data Sharing Statement}

All data generated or analysed during this study are included in this published article (and its supplementary information files).

\section{Ethics Approval and Consent to Participate}

The study was approved by the Bioethics Committee of the Medical University of Bialystok, Poland (permission number APK.002.99.2021). After a detailed explanation of the purpose of our research and the possible risk, all the qualified patients agreed in writing to participate in the experiment.

\section{Acknowledgments}

We are grateful to Martin Lenkiewicz, MSc, for his language assistance.

\section{Author Contributions}

All authors made a significant contribution to the work reported, whether that is in the conception, study design, execution, acquisition of data, analysis and interpretation, or in all these areas; took part in drafting, revising or critically reviewing the article; gave final approval of the version to be published; have agreed on the journal to which the article has been submitted; and agree to be accountable for all aspects of the work.

\section{Funding}

This work was granted by the Medical University of Bialystok, Poland (grant numbers: SUB/1/DN/19/001/ 2209/20; SUB/1/DN/20/005/2209). Dr. Mateusz Maciejczyk was supported by the Foundation for Polish Science (FNP).

\section{Disclosure}

The authors declare that they have no competing interests.

\section{References}

1. World Health Organization: Cancer. 2020. Available from: https:// ww w. who.int/new s-room/fact-sheets/detail/ cancer. Accessed September 07, 2020.

2. Bray F, Ferlay J, Soerjomataram I, et al. Global cancer statistics 2018: GLOBOCAN estimates of incidence and mortality worldwide for 36 cancers in 185 countries. CA Cancer J Clin. 2018;68(6):394-424. doi:10.3322/caac. 21492

3. Ferlay J, Ervik M, Lam F, et al. Global Cancer Observatory: Cancer Tomorrow. Lyon: International Agency for Research on Cancer; 2018. Available from: https://gco.iarc.fr/tomorrow. Accessed September 07, 2020. 
4. Mantur M, Snarska J, Koper O, et al. Serum sICAM, sVCAM and sE-selectin levels in colorectal cancer patients. Folia Histochem Cytobiol. 2009;47(4):621-625.

5. Korniluk A, Kamińska J, Kiszło P, et al. Lectin adhesion proteins (P-, L- and E-selectins) as biomarkers in colorectal cancer. Biomarkers. 2017;22(7):629-634

6. Bufill JA. Colorectal cancer: evidence for distinct genetic categories based on proximal or distal tumor location. Ann Intern Med. 1990;113(10):779-788. doi:10.7326/0003-4819-113-10-779

7. Baran B, Mert Ozupek N, Yerli Tetik N, et al. Difference between left-sided and right-sided colorectal cancer: a focused review of literature. Gastroenterol Res. 2018;11(4):264-273. doi:10.14740/ gr1062w

8. Mena S, Ortega A, Estrela JM. Oxidative stress in environmental-induced carcinogenesis. Mutat Res. 2009;674(12):36-44. doi:10.1016/j.mrgentox.2008.09.017

9. Kurutas EB. The importance of antioxidants which play the role in cellular response against oxidative/nitrosative stress: current state. Nutr J. 2016;15(1):71. doi:10.1186/s12937-016-0186-5

10. Klaunig JE, Wang $\mathrm{Z}, \mathrm{Pu} \mathrm{X}$, et al. Oxidative stress and oxidative damage in chemical carcinogenesis. Toxicol Appl Pharmacol. 2011;254(2):86-99.

11. Korniluk A, Koper O, Kemona H, et al. From inflammation to cancer. Ir J Med Sci. 2017;186(1):57-62. doi:10.1007/s11845-016-1464-0

12. Zińczuk J, Maciejczyk M, Zaręba K, et al. Pro-oxidant enzymes, redox balance and oxidative damage to proteins, lipids and DNA in colorectal cancer tissue. is oxidative stress dependent on tumour budding and inflammatory infiltration? Cancers. 2020;12(6):1636. doi:10.3390/cancers12061636

13. Jass JR, Sobin LH. Histological Typing of Intestinal Tumours. Heidelberg: Springer Berlin Heidelberg; 1989.

14. Lugli A, Kirsch R, Ajioka Y, et al. Recommendations for reporting tumor budding in colorectal cancer based on the International Tumor Budding Consensus Conference (ITBCC) 2016. Mod Pathol. 2017;30 (9):1299-1311. doi:10.1038/modpathol.2017.46

15. Ueno H, Kajiwara Y, Shimazaki H, et al. New criteria for histologic grading of colorectal cancer. Am J Surg Pathol. 2012;36(2):193-201. doi:10.1097/PAS.0b013e318235edee

16. Zalewska A, Knaś M, Zendzian-Piotrowska M, et al. Antioxidant profile of salivary glands in high fat diet-induced insulin resistance rats. Oral Dis. 2014;20(6):560-566. doi:10.1111/odi.12173

17. Kolodziej U, Maciejczyk M, Miasko A, et al. Oxidative modification in the salivary glands of high fat-diet induced insulin resistant rats. Front Physiol. 2017;8:20. doi:10.3389/fphys.2017.00020

18. Benzie IFF, Strain JJ. The ferric reducing ability of plasma (FRAP) as a measure of "antioxidant power": the FRAP assay. Anal Biochem. 1996;239(1):70-76. doi:10.1006/abio.1996.0292

19. Reznick AZ, Packer L. Oxidative damage to proteins: spectrophotometric method for carbonyl assay. Methods Enzymol. 1994;233:357-363

20. Ellman GL. Tissue sulfhydryl groups. Arch Biochem Biophys. 1959;82(1):70-77. doi:10.1016/0003-9861(59)90090-6

21. Klimiuk A, Maciejczyk M, Choromańska M, et al. Salivary Redox Biomarkers in Different Stages of Dementia Severity. J Clin Med. 2019;8(6):840. doi:10.3390/jcm8060840

22. Borys J, Maciejczyk M, Krętowski AJ, et al. The Redox Balance in Erythrocytes, Plasma, and Periosteum of Patients with Titanium Fixation of the Jaw. Front Physiol. 2017;8:386. doi:10.3389/ fphys.2017.00386

23. Johnson R, Baker J. Assay of serum fructosamine: internal vs external standardization. Clin Chem. 1987;33(10):1955-1956. doi:10.1093/clinchem/33.10.1955

24. Kalousová M, Zima T, Tesař V, et al. Advanced glycoxidation end products in chronic diseases - Clinical chemistry and genetic background. Mutat Res. 2005;579(1-2):37-46. doi:10.1016/j. mrfmmm.2005.03.024
25. Kruidenier L, Kuiper I, Van Duijn W, et al. Imbalanced secondary mucosal antioxidant response in inflammatory bowel disease. J Pathol. 2003;201(1):17-27. doi:10.1002/path.1408

26. Grisham MB, Johnson GG, Lancaster JR. Quantitation of nitrate and nitrite in extracellular fluids. Methods Enzymol. 1996;268:237-246.

27. Borys J, Maciejczyk M, Antonowicz B, et al. Glutathione Metabolism, Mitochondria Activity, and Nitrosative Stress in Patients Treated for Mandible Fractures. J Clin Med. 2019;8(1):127. doi: $10.3390 /$ jcm 8010127

28. Beckman JS, Ischiropoulos H, Zhu L, et al. Kinetics of superoxide dismutase- and iron-catalyzed nitration of phenolics by peroxynitrite. Arch Biochem Biophys. 1992;298(2):438-445. doi:10.1016/00039861(92)90432-V

29. Wink DA, Kim S, Coffin D, et al. Detection of S-nitrosothiols by fluorometric and colorimetric methods. Methods Enzymol. 1999;301:201-211.

30. Liebig C, Ayala G, Wilks JA, et al. Perineural invasion in cancer: a review of the literature. Cancer. 2009;115(15):3379-3391.

31. Fiaschi T, Chiarugi P. Oxidative stress, tumor microenvironment, and metabolic reprogramming: a diabolic liaison. Int $J$ Cell Biol. 2012;2012:762825. doi:10.1155/2012/762825

32. Moldogazieva NT, Lutsenko SV, Terentiev AA. Reactive oxygen and nitrogen species-induced protein modifications: implication in carcinogenesis and anticancer therapy. Cancer Res. 2018;78 (21):6040-6047. doi:10.1158/0008-5472.CAN-18-0980

33. Schieber M, Chandel NS. ROS function in redox signaling and oxidative stress. Curr Biol. 2014;24(10):R453-62. doi:10.1016/j. cub.2014.03.034

34. Choromańska B, Myśliwiec P, Łuba M, et al. Impact of weight loss on the total antioxidant/oxidant potential in patients with morbid obesity-a longitudinal study. Antioxidants. 2020;9(5):376. doi:10.3390/antiox9050376

35. Dasuri K, Zhang L, Keller JN. Oxidative stress, neurodegeneration, and the balance of protein degradation and protein synthesis. Free Radic Biol Med. 2013;62:170-185.

36. Lushchak VI. Free radicals, reactive oxygen species, oxidative stress and its classification. Chem Biol Interact. 2014;224:164-175. doi:10.1016/j.cbi.2014.10.016

37. Suzuki YJ, Carini M, Butterfield DA. Protein Carbonylation. Antioxid Redox Signal. 2010;12(3):323-325. doi:10.1089/ars.2009.2887

38. Gillery P, Jaisson S. Usefulness of non-enzymatic post-translational modification derived products (PTMDPs) as biomarkers of chronic diseases. J Proteomics. 2013;92:228-238. doi:10.1016/j.jprot.2013.02.015

39. Stadtman ER, Berlett BS. Reactive oxygen-mediated protein oxidation in aging and disease. Drug Metab Rev. 1998;30(2):225-243. doi: $10.3109 / 03602539808996310$

40. Morabito F, Cristani M, Saija A, et al. Lipid peroxidation and protein oxidation in patients affected by Hodgkin's lymphoma. Mediators Inflamm. 2004;13(5-6):381-383. doi:10.1080/09629350400008760

41. Yilmaz IA, Akçay T, Cakatay U, et al. Relation between bladder cancer and protein oxidation. Int Urol Nephrol. 2003;35(3):345-350. doi:10.1023/B:UROL.0000022920.93994.ba

42. Goswami K, Nandeesha H, Koner BC, et al. A comparative study of serum protein-bound sialic acid in benign and malignant prostatic growth: possible role of oxidative stress in sialic acid homeostasis. Prostate Cancer Prostatic Dis. 2007;10(4):356-359. doi:10.1038/sj. pcan. 4500965

43. Rossner P, Terry MB, Gammon MD, et al. Plasma protein carbonyl levels and breast cancer risk. J Cell Mol Med. 2007;11(5):1138-1148. doi:10.1111/j.1582-4934.2007.00097.x

44. Akira S, Kishimoto T. NF-IL6 and NF-kappa B in cytokine gene regulation. Adv Immunol. 1997;65:1-46.

45. Khansari N, Shakiba Y, Mahmoudi M. Chronic inflammation and oxidative stress as a major cause of age- related diseases and cancer. Recent Pat Inflamm Allergy Drug Discov. 2009;3(1):73-80. doi:10.2174/187221309787158371 
46. Onesti CE, Boemer F, Josse C, et al. Tryptophan catabolism increases in breast cancer patients compared to healthy controls without affecting the cancer outcome or response to chemotherapy. J Transl Med. 2019;17(1):239. doi:10.1186/s12967-019-1984-2

47. Venkateswaran N, Conacci-Sorrell M. Kynurenine: an oncometabolite in colon cancer. Cell Stress. 2020;4(1):24-26. doi:10.15698/ cst2020.01.210

48. Ahmad S, Khan H, Siddiqui Z, et al. AGEs, RAGEs and s-RAGE; friend or foe for cancer. Semin Cancer Biol. 2018;49:44-55. doi:10.1016/j.semcancer.2017.07.001

49. Choromańska B, Myśliwiec P, Łuba M, et al. Bariatric surgery normalizes protein glycoxidation and nitrosative stress in morbidly obese patients. Antioxidants. 2020;9(11):1087. doi:10.3390/ antiox 9111087

50. Mémet S. NF-кB functions in the nervous system: from development to disease. Biochem Pharmacol. 2006;72(9):1180-1195. doi:10.1016/ j.bcp.2006.09.003

51. Nomura A, Majumder K, Giri B, et al. Inhibition of NF-kappa B pathway leads to deregulation of epithelial-mesenchymal transition and neural invasion in pancreatic cancer. Lab Investig. 2016;96 (12):1268-1278. doi:10.1038/labinvest.2016.109

52. Ott C, Jacobs K, Haucke E, et al. Role of advanced glycation end products in cellular signaling. Redox Biol. 2014;2:411-429. doi:10.1016/j.redox.2013.12.016

53. Supruniuk E, Maciejczyk M, Zalewska A, et al. Blood profile of cytokines, chemokines, growth factors, and redox biomarkers in response to different protocols of treadmill running in rats. Int J Mol Sci. 2020;21(21):8071. doi:10.3390/ijms21218071

54. Fenga C, Gangemi S, Teodoro M, et al. 8-Hydroxydeoxyguanosine as a biomarker of oxidative DNA damage in workers exposed to low-dose benzene. Toxicol Rep. 2017;4:291-295. doi:10.1016/j. toxrep.2017.05.008

55. Hansen IO, Jess P. Possible better long-term survival in left versus right-sided colon cancer - a systematic review. Dan Med J. 2012;59 (6):A4444.
56. Korde Choudhari S, Chaudhary M, Bagde S, et al. Nitric oxide and cancer: a review. World J Surg Oncol. 2013;11(1):118. doi:10.1186/ 1477-7819-11-118

57. Xu W, Liu LZ, Loizidou M, et al. The role of nitric oxide in cancer. Cell Res. 2002;12(5-6):311-320. doi:10.1038/sj.cr.7290133

58. Nakamura Y, Yasuoka H, Tsujimoto $M$, et al. Nitric oxide in breast cancer: induction of vascular endothelial growth factor-C and correlation with metastasis and poor prognosis. Clin Cancer Res. 2006;12 (4):1201-1207. doi:10.1158/1078-0432.CCR-05-1269

59. Feng CW, Wang LD, Jiao LH, et al. Expression of p53, inducible nitric oxide synthase and vascular endothelial growth factor in gastric precancerous and cancerous lesions: correlation with clinical features. BMC Cancer. 2002;29(2):8. doi:10.1186/1471-2407-2-8

60. Bartesaghi S, Radi R. Fundamentals on the biochemistry of peroxynitrite and protein tyrosine nitration. Redox Biol. 2018;14:618-625. doi:10.1016/j.redox.2017.09.009

61. Williams EL, Djamgoz MBA. Nitric oxide and metastatic cell behaviour. Bioessays. 2005;27(12):1228-1238. doi:10.1002/ bies. 20324

62. Lala PK, Chakraborty C. Role of nitric oxide in carcinogenesis and tumour progression. Lancet Oncol. 2001;2(3):149-156.

63. Eiserich JP, Baldus S, Brennan ML, et al. Myeloperoxidase, a leukocyte-derived vascular NO oxidase. Science. 2002;296 (5577):2391-2394. doi:10.1126/science. 1106830

64. Choromańska B, Myśliwiec P, Łuba M, et al. The impact of hypertension and metabolic syndrome on nitrosative stress and glutathione metabolism in patients with morbid obesity. Oxid Med Cell Longev. 2020;2020:1057570.

65. Panagopoulos V, Leach DA, Zinonos I, et al. Inflammatory peroxidases promote breast cancer progression in mice via regulation of the tumour microenvironment. Int $J$ Oncol. 2017;50(4):1191-1200. doi:10.3892/ijo.2017.3883

66. Rymaszewski A, Tate E, Yimbesalu J, et al. The role of neutrophil myeloperoxidase in models of lung tumor development. Cancers. 2014;6(2):1111-1127. doi:10.3390/cancers6021111

\section{Publish your work in this journal}

Cancer Management and Research is an international, peer-reviewed open access journal focusing on cancer research and the optimal use of preventative and integrated treatment interventions to achieve improved outcomes, enhanced survival and quality of life for the cancer patient.
The manuscript management system is completely online and includes a very quick and fair peer-review system, which is all easy to use. Visit http://www.dovepress.com/testimonials.php to read real quotes from published authors. 